\title{
Modernist enamels: composition, microstructure and stability
}

\author{
Martí Beltrán ${ }^{1}$, Nadine Schibille ${ }^{2}$, Fiona Brock ${ }^{3}$, Bernard Gratuze ${ }^{2}$, \\ Oriol Vallcorba ${ }^{4}$ and Trinitat Pradell ${ }^{1}$ \\ ${ }^{1}$ Physics Department and Barcelona Research Centre in Multiscale Science and Engineering, \\ Universitat Politècnica de Catalunya, Campus Diagonal Besòs, Av. Eduard Maristany, 10-14 \\ 08019 Barcelona, Spain \\ ${ }^{2}$ IRAMAT-Centre Ernest-Babelon, UMR 5060 CNRS, 3D rue de la Férollerie, 45071 Orléans \\ cedex 2, France \\ ${ }^{3}$ Cranfield Forensic Institute, Cranfield University, Defence Academy of the United Kingdom, \\ Shrivenham, SN6 8LA, UK \\ ${ }^{4}$ ALBA Synchrotron, Carrer de la Llum 2-26, 08290 Cerdanyola del Vallès, Barcelona, Spain
}

\begin{abstract}
Coloured enamels from the materials used in Modernist workshops from Barcelona were produced and compared to those found in the buildings to explore the reason for the reduced stability of the blue and green enamels.

They were made of a lead-zinc borosilicate glass with a low softening point, reasonable stability to corrosion and matching thermal expansion coefficient with the blown base glass, mixed with colourants and pigment particles. The historical enamels show a lead, boron and zinc depleted silica rich amorphous glass, with precipitated lead and calcium sulphates or carbonates, characteristic of extensive atmospheric corrosion. The blue and green enamels show a heterogeneous layered microstructure more prone to degradation which is augmented by a greater heating and thermal stress affectation produced by the enhanced Infrared absorbance of blue tetrahedral cobalt colour centres and copper ions dissolved in the glass and, in particular, of the cobalt spinel particles.
\end{abstract}

Keywords: lead zinc borosilicate glass; colourants; pigments; microstructure; atmospheric corrosion 


\section{Introduction}

Enamels applied over transparent glasses, ceramics and metallic surfaces have been used since ancient times as they provided a wider variety of artistic effects compared to other decorative techniques. They were made of crushed glass to which transition metals and pigment particles were added to produce a wide range of transparent, translucent hues and opaque paints. In the $19^{\text {th }}$ century and linked to the emergence of the decorative arts (Art Nouveau) [1] a renewed interest in the use of enamels, in particular for the decoration of glass appeared. The Modernist movement ( $1885-$ 1920) was particularly innovative in Catalonia, above all in Barcelona. During the second half of the $19^{\text {th }}$ century the development of new glass compositions, processes of synthesis and the understanding of light absorption gave rise to the production of new materials with a wider range of colours and compositions. This led eventually to the consequent proliferation of enamel manufacture industries, local porcelain and stained glass workshops [2]. Some of the most important manufacturing companies from the period were Wengers, Lacroix and L'Hospied. Adolphe Lacroix was at the forefront of developing a new type of enamel, as described in his 1872 treatise "Des couleurs vitrifiables et de leur employ pour la peinture sur porcelain, faience, vitraux" [3]. Wengers was a British company established in Etruria, Stoke-on-Trent, by Albert Francis Wenger (c. 1840-1924). Thompson L'Hospied \& Co Ltd was founded near Stourbridge, UK, by Charles Herbert Thompson, a chemist with commercial interests in England and France [4].

The enamels applied over stained glasses, ceramics or metals located on exterior walls have been exposed to the atmosphere and solar irradiation. Enamel deterioration is particularly serious as their damage results in the loss of colour or even flaking. Some of the $16^{\text {th }}$ and $17^{\text {th }}$ century compositions were found to be unstable [5]; the firing temperatures might have been too low for an adequate fixation [5], or differential thermal expansion coefficients of the enamels and base material resulted in the formation of cracks and subsequent flaking off of the enamels $[6,7]$. Moreover, the use of a lead-borate obtained from a solution of borax and lead nitrate since the second half of the $18^{\text {th }}$ century [8] to reduce the softening temperature of the enamel resulted in a material which was particularly sensible to moisture corrosion. The discolouration 
of the enamels has recently been associated with lead leaching and subsequent precipitation of a white compound, lead carbonate [9]. Generally speaking, the low stability of lead and lead borate enamels prone to water corrosion has been widely regarded as the main cause of their deterioration [8].

However, enamel deterioration seems to have affected blue and green enamels in a particular way [6-11]. For instance, the blue and green enamels produced in the Modernist period (1885-1920) by famous stained glass workshops in Barcelona appear often more deteriorated than other colours, even when found in the same object, Figure 1. The use of smalt, a high lead-potash cobalt glass, in the blue enamels has been given as one of the main reasons for their discolouration; discolouration of smalt is due to the leaching of $\mathrm{K}^{+}$in a humid environment which results in the change of the cobalt ions from blue tetrahedral to pink octahedral coordination [10]. However, our studies have shown that smalt was not used in the Modernist Catalan enamelled glass [12], probably because the discolouration of smalt was already well known by then.

In order to assess the role of the composition of the enamels and base glasses and the firing temperature in the degradation of the blue and green enamels applied over stained glasses from the Catalan Modernist workshops, we conducted a multitechnique investigation of the enamels used by Rigalt, Granell \& Cia., one of the most important Modernists workshops in Barcelona [12]. The company was founded in 1890 by Antoni Rigalt i Blanch (1850-1914) and Jeroni F. Granell i Manresa (1868-1923), later Granell \& cia (1923-1931) [2]. Before closing in 1931, the materials were acquired by J.M. Bonet Vitralls S.L., a stained glass company dedicated to the production and restoration of stained glass since 1923. The glass composition and the thermal properties (i.e. glass transition, deformation and softening temperatures) were determined. Our study [12] demonstrated that the enamels were "ready-for-use" and had been manufactured by various companies from all over Europe, even though the mixture of enamels and the modification of their composition can also be expected. The blue and green enamels were made of a lead-zinc borosilicate glass (30-40 \% PbO, 0-15\% $\mathrm{ZnO}, 15-19 \% \mathrm{~B}_{2} \mathrm{O}_{3}$ ) with softening temperatures varying between $583^{\circ} \mathrm{C}$ and $617^{\circ} \mathrm{C}$, mixed with colourants or pigment particles [12]. These compositions are characterised by their low sintering temperatures and a reasonable stability against 
water corrosion [13]. The glass transition temperature determined from contemporary blown base glass is very close $\left(575^{\circ} \mathrm{C}\right)$ to the softening temperatures of the enamels which leaves a relatively narrow firing temperature range. Nevertheless, the high stability and resistance to water corrosion of the enamels studied, and the fact that a similar enamel glass composition is expected to have been used for the production of the other colours, suggests a different reason for the greater deterioration shown by the blue and green enamels.

In this paper, a collection of different coloured enamels was produced from the $19^{\text {th }}$ century materials found in the Rigalt \& Granell workshop and analysed in order to explore the reason for the reduced stability of the blue and green enamels as compared to the other colours. Two fragments of enamelled glasses produced by the same workshop in the first decade of the $20^{\text {th }}$ century from the exterior of two main buildings in Barcelona that have been affected by atmospheric corrosion were also investigated. Finally, another fragment of enamelled glass produced by a contemporary workshop active in the city, Maumejan, and which was kept inside a building was also studied.

Laser Ablation Inductively-Coupled Plasma Mass Spectrometry (LA-ICP-MS) was used to determine the chemical composition of the replica enamels, the historical enamels, and the base glasses. Polished cross sections of the enamelled glasses were also analysed by Scanning Electron Microscopy (SEM) with an Energy Dispersive Spectroscopy detector (EDS) to determine the microcrystalline pigment and reaction particles, and by Focus Ion Beam (FIB) to establish the presence of pigment nanoparticles. The crystalline compounds present in the replica enamels were determined by conventional X-ray Diffraction (XRD) and those from the historical glasses by $\mu$-XRD with synchrotron light. The colour and nature of the colourants have also been investigated by Ultraviolet Visible and Near Infrared (UV-Vis-NIR) spectroscopy using Diffuse Reflectance and Transmission modes respectively.

\section{Materials and methods}

The materials studied belong to the collection of J.M. Bonet Vitralls S.L. and includes the documentation and materials used to produce five different coloured enamels 
from the Rigalt, Granell \& cia workshop. The containers with the enamel powder had labels from various manufacturing companies from the period such as Wengers, Lacroix and L'Hospied. A collection of 16 transparent and semi-opaque purple, red, yellow, blue and green replica enamels and a grisaille were prepared by applying the enamel/grisaille powder mixed with water with a brush over a blown base glass (similar to the base glasses used in this historical period). The painted glass was first heated to $400^{\circ} \mathrm{C}$ for over two hours, kept at this temperature for 30 minutes, then heated at a constant rate of $2.5^{\circ} \mathrm{C} / \mathrm{min}$ to $590^{\circ} \mathrm{C}$, kept at this temperature for 20 minutes and, finally, left to cool naturally to room temperature ( 24 hours).

Two fragments of enamelled glasses produced by the Rigalt, Granell \& cia. workshop from two main buildings in the city of Barcelona, Palau de Justicia (High Court Palace), 1911-1914, and Seu del Districte Sants-Montjuic (Town hall of the Sants-Montjuic District), 1915, which have recently been restored were also studied. The enamelled glass of a skylight from Palau de Justicia consists of purple enamel surrounded by grisaille contour lines (PJ1) and that of a window from the Seu del Districte SantsMontjuic (SM1) has a blue enamel over which grisaille has been applied to give some opacity and artistic effects. Finally, a fragment produced by the Maumejan workshop, active in the city since 1907, from an inner panel at Estació del Nord (North station), 1910-1912, has green and yellow enamels and a grisaille applied on the other side of the base blown glass.

The composition of the powders and replica enamels prepared from them belonging to the Rigalt, Granell \& cia workshop was determined by LA-ICP-MS at the Cranfield Forensic Institute using a direct solid laser ablation sampling system ( $Q$ switched Nd:YAG ESI $213 \mathrm{~nm}$ laser ablation system, New Wave Research) coupled to a quadrupole ICP-MS (Thermo Scientific XSERIES 2), operating in standard mode. After placing the samples in the ablation chamber (flushed with He at a rate of $500 \mathrm{ml} \cdot \mathrm{min}^{-}$ $\left.{ }^{1}\right)$, the targets were ablated with $20-50 \mathrm{~s}$ spot-mode analyses with a spot size of $80 \mu \mathrm{m}$ on the frontal section of the applied enamel at $10 \mathrm{~Hz}$ laser frequency, fluency of ca. 12 $\mathrm{J} / \mathrm{cm}^{2}$ and $20 \mathrm{~ms}$ dwell time per amu. Three spot replicates were undertaken per analysis, with 15 sweeps per replicate. Several analyses on the dry gas were carried out in each set to establish the background prior to ablation. A pre-ablation time of $15-20 \mathrm{~s}$ 
was selected in order to remove surface contaminants. Instrumental drift was monitored throughout the analysis by measuring synthetic certified reference glasses (NIST 612 and 610) up to every 9 measurements within each run. To improve the instrument sensitivity, lower background noise, and reduce oxidised species, the ICP parameters (including RF power, ion lens voltage and sampling position within the plasma, extraction voltage, and gas flow rates) were fine-tuned at the beginning of every set of analysis by continuously ablating on a reference glass (NIST 612) using the same working conditions chosen for the analyses. The internal standard independent (ISI) method was used to calculate the elemental concentration [14]. Within this method the summation of the element oxides is assumed to constitute $100 \%$ of the sample. The accuracy was evaluated with respect to Corning Museum of Glass (CMG) A.

The historical enamels and also some of the replica enamels were analysed by LA-ICPMS in the IRAMAT-CEB at the CNRS, Orléans (France), using a Resonetics M50E excimer laser (ArF, $193 \mathrm{~nm}$ ) equipped with a S155 ablation cell and a Thermo Fisher Scientific ELEMENT XR mass spectrometer system. The ablations were typically carried out with a $5 \mathrm{~mJ}$ energy a $10 \mathrm{~Hz}$ pulse frequency in spot-mode and a beam diameter of $100 \mu \mathrm{m}$ for the base glass. The enamels were typically analysed along the surface due to insufficient thickness with a beam diameter of $50 \mu \mathrm{m}$ that was occasionally reduced down to $25 \mu \mathrm{m}$ when saturation of the signal caused by high concentrations transition metals occurred. A pre-ablation time of either $10 \mathrm{~s}$ or $20 \mathrm{~s}$ depending on the thickness of the sample was followed by $30 \mathrm{~s}$ signal acquisition, resulting in 10 mass scans. The ablated material is transported to the plasma torch by an argon/helium flow at an approximate rate of $1 \mathrm{~L} / \mathrm{min}$ for $\mathrm{Ar}$ and $0.65 \mathrm{~L} / \mathrm{min}$ for He. The ion signals in countsper-second are recorded for 58 isotopes (from Li to U). Standard Reference Material (NIST SRM610) as well as Corning glasses B, C, and D and APL1 (in-house standard glass) were used for external calibration, while ${ }^{28} \mathrm{Si}$ was used as internal standard. Quantitative concentrations were calculated based on the procedures described by Gratuze [14]. Precision and accuracy are reflected in the repeated measurements of reference glasses Corning A and NIST SRM612. 
Polished cross sections of the sherds were prepared and coated with a sputtered carbon layer ( $<20 \mu \mathrm{m}$ thick). The polished sections were examined at the Universitat Politècnica de Catalunya (Barcelona) both in reflected light with an optical microscope $(\mathrm{OM})$, and in a crossbeam workstation (Zeiss Neon 40) equipped with scanning electron microscopy (SEM) GEMINI (Shottky FE) column with attached EDS (INCAPentaFETx3 detector, 30 $\mathrm{mm}^{2}$, ATW2 window, resolution $123 \mathrm{eV}$ at the $\mathrm{Mn} \mathrm{K} \alpha$ energy line), operated at $20-\mathrm{kV}$ accelerating voltage with $1.1 \mathrm{~nm}$ lateral resolution, 20 $\mathrm{nA}$ current, $7 \mathrm{~mm}$ working distance, and $120 \mathrm{~s}$ measuring times. The EDS data was calibrated using mineral standards and verified with glass standards (K299, K93a, SRM612 and K252 from Geller MicroÅnalytical Laboratory, Inc.). The enamel microstructures were studied and recorded in back-scattered electron (BSE) mode in which the different phases present could be distinguished on the basis of their atomic number contrast. BSE images of the microstructures were obtained at $20 \mathrm{kV}$ acceleration voltage. FIB was used to polish the surface and to obtain high resolution images of nanoparticles when present in the enamels.

XRD analysis of the powders and enamels prepared from the Rigalt, Granell \& cia workshop materials was also performed to determine the presence and nature of crystalline particles. The surface of the enamels was directly analysed using a PANalytical X'Pert PROMPD Alpha1 powder diffractometer with Bragg-Brentano $\theta / 2 \theta$ and $\mathrm{Cu}-\mathrm{K} \alpha$ radiation. Measuring conditions were $4^{\circ}-100^{\circ} 2 \theta$, with a step size of $0.017^{\circ}$ and measuring time of $150 \mathrm{~s}$.

Synchrotron X-ray microdiffraction ( $\mu$-XRD) data from the historical enamels and also from some cross sections of the enamels prepared from the Rigalt, Granell \& cia workshop materials were collected in the Materials Science and Powder Diffraction beamline (MSPD BL04) [15] at the ALBA Synchrotron Light (Cerdanyola, Spain) using polished thin cross sections (about $100 \mu \mathrm{m}$ thick) of the enamelled glasses in transmission geometry, using $0.4246 \AA$ wavelength $(29.2 \mathrm{keV})$, a $20 \times 20 \mu \mathrm{m}^{2}$ spot size, and a CCD camera, SX165 (Rayonix, L.L.C., Evanston, IL) detector.

UV-Vis Transmittance and Diffuse Reflectance (with ISR 3100 Ulbricht integrating sphere) measurements were obtained using a double beam UV-Vis spectrophotometer 
(Shimadzu 2700) with a spot size of $3 \mathrm{~mm} \times 1 \mathrm{~mm}$ recorded between $200 \mathrm{~nm}$ and 800 $\mathrm{nm}$; barium sulphate was used as a white standard for the reflectance measurements and calculation of the colour coordinates. NIR transmittance measurements were obtained using a double beam UV-Vis spectrophotometer (Shimadzu 3600) with a spot size of $8 \mathrm{~mm} \times 1 \mathrm{~mm}$ recorded between $800 \mathrm{~nm}$ and $3000 \mathrm{~nm}$.

\section{Results and Discussion}

\subsection{The Rigalt, Granell \& cia enamel replicas}

The LA-ICP-MS data of the replica enamels (Table 1) show that the enamel glass phase composition is a $\mathrm{PbO}-\mathrm{B}_{2} \mathrm{O}_{3}-\mathrm{SiO}_{2}-\mathrm{ZnO}$ type to which the pigment particles and/or colourants have been added. The pigment particles determined by XRD are shown in Table 2, the JCPDS-PDF numbers of the files used for the identification are given in brackets; SEM-BSE images of polished cross-sections and $\mu$-XRD patterns of different coloured enamels are shown in Fig. $\mathbf{2}$ and Fig. 3, and those corresponding to the grisaille in Fig. 4. The colourants were determined by UV-Vis-NIR spectroscopy in Transmission mode, and the corresponding optical density spectra, $O D=\log (1 / T)$, are shown in Fig. 5A and the NIR spectra in Fig. 5B. Finally, the Lab* colour coordinates of the enamels has been calculated from the Diffuse Reflectance UV-Vis spectra and are given in Table 3.

LA-ICP-MS data of the purple enamels (E14 and E107) show that they contain traces of silver and gold and about $2 \%$ of $\mathrm{SnO}_{2}$. FE-SEM images of the cross sections (Fig. $2 \mathrm{~A}$ and 2B), show a suspension of small "drops" containing small $(\approx 10 \mathrm{~nm})$ nanoparticles rich in $\mathrm{Ag}, \mathrm{Au}$ and $\mathrm{Sn}$. The single peak with a maximum absorbance at $503 \mathrm{~nm}$ in the transmission UV-Vis spectrum, Fig. 5A, indicates that the nanoparticles are a silvergold alloy [16] of approximate composition 49 at\% $\mathrm{Ag} /(\mathrm{Ag}+\mathrm{Au})$, calculated assuming a linear relationship between the position of the absorption bands for $\mathrm{d} \approx 10 \mathrm{~nm}$ silver and gold nanoparticles in a medium with an index of refraction of about $1.7, \approx 440 \mathrm{~nm}$ and $\approx 560 \mathrm{~nm}$ respectively; the corresponding XRD pattern shows also the presence of $\mathrm{SnO}_{2}$. The results indicate that the purple pigment was of the type known as Purple of 
Cassius [17]. Purple of Cassius is a co-precipitate of gold and $\mathrm{SnO}_{2}$; gold is dissolved with aqua regia or added as gold chloride together with hydrated tin oxide which acts as a protector and stabiliser of colloidal gold. In this case silver and gold were dissolved together and the pigment produced is thus a silver-gold alloy. Lacroix describes the addition of silver in the 1872 treatise in order to modify the hue of the enamel [3]. Moreover, Rigalt described a mixture of auric chloride and silver chloride which was added to the flux (the high lead-borosilicate glass in Table 1) in various proportions [18] to obtain a range of purple to carmine colours. In fact, the colour of the enamel E14 is actually red rather than purple $\left(a^{*}=56.5\right)$, Table 3 .

Three different types of red enamels were identified: one is associated with Se and Cd (E23), one with $\mathrm{Cr}$ and $\mathrm{Pb}$ (E25), and the third associated with manganese (E124). The XRD pattern corresponding to E23 shows mainly the presence of cadmium sulphide selenide, $\mathrm{CdS}_{x} \mathrm{Se}_{1-x}$, and also some $\mathrm{CdS}$ and $\mathrm{CdSe}$ particles together with cassiterite (Fig. 2C and 2D). CdS and CdSe form a complete solution, the main phase determined by XRD has a wurtzite structure with lattice parameters $(a=b=4.19 \AA$ and $c=6.82 \AA$ ) matching a composition close to $x=0.79$. The colour ranges from yellow (pure CdS), to orange for $x=0.81$, red for $x=0.65$ and brown for $x=0.25$ [19]. The chemical composition of the cadmium sulphide selenide particles has been defined by SEM-EDS. Unfortunately, the S content cannot be accurately determined because of interference from lead in the surrounding matrix. However, the cadmium and selenium content can be determined, giving $0.29 \pm 0.04 \mathrm{Se}$ atoms for each $\mathrm{Cd}$ atom. The composition is adequate to obtain a red ruby colour at a temperature close to the enamels firing temperature $\left(\approx 590^{\circ} \mathrm{C}\right)$. Higher firing temperatures favour the formation of crystals richer in Se, and lower firing temperatures produce crystals richer in $S$ [19]. Consequently, the colour may change from red to orange if the firing temperature is too low. The reactivity of the pigment with the glass is also something to take into account, as $\mathrm{ZnO}$, zinc silicates or lead sulphides or sulphates can be formed [17]. In fact, the presence of $\mathrm{ZnO}$ and small unidentified phases are observed in the XRD pattern (Fig. 2D). Enamel E25 contains $\mathrm{Cr}$ and higher levels of $\mathrm{Pb}$ than the other enamels. The XRD pattern shows the presence of phoneicochroite, $\mathrm{PbO} \cdot \mathrm{Pb}\left(\mathrm{CrO}_{4}\right)$, particles (Fig. 2F), a basic lead chromate which bestows a coral red colour to the glass. 
The particles are large and rounded indicating some degree of dissolution in the glass (Fig. 2E). Small cassiterite particles which increase the opacity are also present. Finally, E124 contains $\mathrm{Mn}^{3+}$, [17] (Fig. 5A) and has no crystalline particles. It consequently has a lower lightness $\left(L^{*}\right)$ compared to the other red enamels and is in fact purple rather than red (Table 3).

The yellow enamels E3, E4 and E119 contain hexavalent chromium, $\mathrm{Cr}^{6+}$, dissolved in the glass as colourant [20] (Fig. 3A and Fig. 5) and E119 also exhibits cassiterite particles. The E4 and E119 glassy matrix is a lead-zinc borosilicate while E3 is zinc free and has lower $\mathrm{B}_{2} \mathrm{O}_{3}$ and higher $\mathrm{Na}_{2} \mathrm{O}$ and $\mathrm{CaO}$ contents. Hexavalent chromium is responsible for the high absorption in the ultraviolet region extending to $500 \mathrm{~nm}$ (Fig. 5A) bringing about the yellow-greenish colour shown by the enamels (Table 3). E106, contains $\mathrm{Sb}$, as well as $\mathrm{Sn}$ and $\mathrm{Fe}$ in smaller amounts. The enamel has lower $\mathrm{B}_{2} \mathrm{O}_{3}$ and $\mathrm{ZnO}$ content than the other enamels. The XRD pattern shows the presence of particles of lead antimony oxide with a pyrochlore structure, $\mathrm{Pb}_{2}(\mathrm{Sn}, \mathrm{Sb})_{2} \mathrm{O}_{7}$. The presence of small amounts of tin and iron are known to help the stability of the pyrochlore structure in the glass [21]. The microcrystalline lead antimonate particles are responsible for the broad scattering with a maximum at $500 \mathrm{~nm}$, and consequently of the yellow colour and opacity of the enamel.

With regard to the green enamels, E34 is lower in $\mathrm{B}_{2} \mathrm{O}_{3}$ and $\mathrm{ZnO}$ than the other green enamels and contains cochromite particles, a spinel of cobalt and chromium $\left(\mathrm{Co}(\mathrm{Cr}, \mathrm{Al})_{2} \mathrm{O}_{4}\right)$ with composition determined by SEM-EDS, observed to vary between 0.6-0.8 atoms of $\mathrm{Al}$ and 1.4-1.2 atoms of $\mathrm{Cr}$, together with yellow particles of lead antimonate in the form of $\mathrm{Pb}_{2}(\mathrm{Sn}, \mathrm{Sb})_{2} \mathrm{O}_{7}$ (Fig. 3B). The Absorbance spectrum shows the three characteristic absorption peaks of $\mathrm{Co}^{2+}$ ions in fourfold coordination at 570 $\mathrm{nm}, 615 \mathrm{~nm}$ and $662 \mathrm{~nm}$ (Fig. 5A) (the triple band is attributed to a Jahn-Teller distortion of the tetrahedral structure), shifted slightly to higher wavelengths compared to a pure cobalt aluminate [22], and which are responsible for the bluegreen colour. E89 contains mainly copper dissolved in the glass matrix. $\mathrm{Cu}^{2+}$ is known to have a large absorption and broad band with a nearly total absorption at $800 \mathrm{~nm}$ (Fig. 5A) extending to the near infrared (1000 nm) (Fig. 5B), which together with the presence of cuprous ions are responsible for the $U$ shaped profile of the absorbance 
with a maximum transmission at about $500 \mathrm{~nm}$, and which gives the green colour to the enamel [17]. Finally, E121, contains cobalt and chromium ions dissolved in the glass. Blue $\left(\mathrm{CoO}_{4}\right)$ groups in the glass show three characteristic very intense absorption peaks in the 500-650 $\mathrm{nm}$ range and which exact positions and intensities depend mainly on the composition of the glass; the shoulder at $479 \mathrm{~nm}$ is related to transitions between the octahedral and tetrahedral sites. $\mathrm{Cr}^{3+}$ is known to give a dark green colour to the glass due to the characteristic absorption bands between $600-700 \mathrm{~nm}[20]$, but if the glass is fired under oxidising conditions, it is difficult to avoid the presence of $\mathrm{Cr}^{6+}$ [17]; in fact lead oxide exerts a stabilising action on hexavalent chromium [17]. The UVVis spectrum of E121 shows that the addition of chromium blue shifts and broadens the triple $\mathrm{Co}^{2+}$ absorption band, producing a green transparent colour. Moreover, we can also observe an enhanced absorbance in the NIR range between 1250 and 1750 $\mathrm{nm}$ related to the presence of $\mathrm{Co}^{2+}$.

All the blue enamels contain cobalt, $\mathrm{Co}^{2+}$, either as particles of a cobalt aluminate with a spinel structure $\mathrm{CoAl}_{2} \mathrm{O}_{4}$ as in enamels E33 (Fig. 3C and 3D), in a very low amount as in E115 or dissolved in the glass, as seen in enamels E122 and E114. E114 and E115 also contain cassiterite particles to increase the opacity. E122 is richer in PbO with very low $\mathrm{B}_{2} \mathrm{O}_{3}$ and $\mathrm{ZnO}$. All the absorbance spectra show the characteristic triple absorption band of $\mathrm{CoO}_{4}$ groups (Fig. 5A) the peak positions varying with glass compositions from a dark blue of E122 to a blue-violet of E33. Another important characteristic is the enhanced NIR response (Fig. 5B) in the range 1250-1750 nm, which is particularly high in the enamels containing $\mathrm{CoAl}_{2} \mathrm{O}_{4}$ particles [22]; $\mathrm{E3} 3$ shows an increase in absorption in this region of about $30 \%$. This enhanced NIR absorption is seen in all the cobaltcontaining enamels, whether green or blue (Fig. 5B). The transparent base glass shows also a broad enhanced NIR absorbance in the range 1000-1500 nm (Fig. 5B) which is related to the presence of $\mathrm{Fe}^{2+}$, well known for its NIR absorption [23]. Nevertheless, the effect is low compared to the absorbance shown by the cobalt containing green and blue enamels, mainly because the iron content of the base glasses of the period is very low (not higher than $0.2 \%$ ) and part of it is present as $\mathrm{Fe}^{3+}$.

Another interesting aspect is that the $\mathrm{CoAl}_{2} \mathrm{O}_{4}$ particles have low density $\left(3.8 \mathrm{~g} / \mathrm{cm}^{3}\right)$ compared to the glass. This is why the particles tend to float and accumulate on the 
surface (Fig. 3C). An interesting consequence of this is that the enamel shows a layered structure, with a lead rich layer at the enamel-glass interface ( $54 \% \mathrm{PbO}$ and negligible amounts of boron as total SEM-EDS analysis add to 98\%). This effect can also be seen although to a lesser extent in the green enamel E34 which contains $\mathrm{CoCr}_{0.6} \mathrm{Al}_{1.4} \mathrm{O}_{4}$ particles (density $\sim 4.7 \mathrm{~g} / \mathrm{cm}^{3}$ ) with a lead rich interface layer ( $48 \% \mathrm{PbO}$ and negligible amounts of boron), Figure 3B. It does not occur in enamels with particles of $\mathrm{PbO} \cdot \mathrm{Pb}\left(\mathrm{CrO}_{4}\right)$ or CdSSe (density of $5.3 \mathrm{~g} / \mathrm{cm}^{3}$ and $5.1 \mathrm{~g} / \mathrm{cm}^{3}$ respectively) (Fig. 2C and 2E) or in particle free enamels (Fig. 3A).

The enamels are made of a glass mixed with colourants and/or pigment particles. In all cases the glass is a high lead glass, but it also contains as major elements $\mathrm{B}, \mathrm{Si}$ and $\mathrm{Zn}$. The amount of $\mathrm{Al}, \mathrm{Mn}$ and $\mathrm{Fe}$ is high only in those enamels where they are present within particulate matter, rather than in the glassy phase. $\mathrm{Mg}, \mathrm{K}, \mathrm{Ca}$ concentrations are very low (normally well below $0.5 \%$ ). Some enamels contain up to $2 \% \mathrm{Na}_{2} \mathrm{O}$, the presence of which is mainly associated with impurities present in the sand and other glass ingredients, but also to some degree to the interaction between the base glass (rich in $\mathrm{Na}$ and $\mathrm{Ca}$ ) and the enamel.

The enamels can be classified into various types depending on the composition of the glassy component. The main group includes E14, E107, E23, E25, E124, E131, E4, E89, E121, E33, E114, E115 and has a base glass composition of $19 \% \mathrm{~B}_{2} \mathrm{O}_{3}, 57 \% \mathrm{PbO}, 14 \%$ $\mathrm{ZnO}, 11 \% \mathrm{SiO}_{2}$. A second group with less zinc (about $4 \% \mathrm{ZnO}$ ) comprises a green (E34) and a yellow (E106) enamel both with lead antimonate particles. A third group contains two enamels (E3 and E122), which are poorer in $\mathrm{B}_{2} \mathrm{O}_{3}$ and $\mathrm{ZnO}$ free. The valency of chromium is known to be quite sensitive to the composition of the glass, in particular to the presence of boron [17]; the yellow colouration of E3, with $(1.3 \%$ $\left.\mathrm{Cr}_{2} \mathrm{O}_{3}\right)$, indicates the presence of $\mathrm{Cr}^{6+}$ and corresponds to the low boron concentration. E122 is a high lead cobalt blue glass, to which the cobalt was added in the form of cobalt aluminate particles which were dissolved in the enamel.

In summary, the enamels are lead-zinc borosilicate glasses to which pigment particles or transition metal ions were added. Borosilicate glasses were invented at the end of the $19^{\text {th }}$ century contemporarily to the invention of our ready-to-use enamels. The 
addition of $\mathrm{PbO}$ and/or $\mathrm{ZnO}$ to the borosilicate glass produces a low-melting glass which may be used as solder [24]. Boric oxide glasses have a structure formed by $\mathrm{BO}_{3}$ triangles which is weaker than the tetrahedral structure of $\mathrm{SiO}_{4}$ silicate glasses. The addition of $\mathrm{B}_{2} \mathrm{O}_{3}$ to a silicate glass gives rise to the formation of tetrahedral $\mathrm{BO}_{4}$ units which is accompanied by an increase in the chemical resistance, decrease of the thermal expansion and enlargement of the softening temperature range. $\mathrm{PbO}$ and $\mathrm{ZnO}$ act as a network-modifier. Depending on the type/amount of network-modifier, a maximum of $\mathrm{BO}_{4}$ units is reached $[13,25]$ and equilibrium is established between trigonal and tetrahedral metaborate. A dense transparent glass with a low softening temperature and a thermal expansion coefficient matching those of the base glass while retaining a good resistance to water corrosion is obtained for compositions of 30-40 mol\% PbO and $\mathrm{B}_{2} \mathrm{O}_{3}: \mathrm{SiO}_{2}$ ratios between 2:1 to $2: 3[13,26]$; zinc borosilicate glasses are also obtained with $\mathrm{B}_{2} \mathrm{O}_{3}: \mathrm{SiO}_{2}: \mathrm{ZnO}=30: 20: 50,30: 10: 60$ and 20:20:60 molar ratios [27].

The composition of our enamels matches closely those of the solder lead-zinc borosilicate glasses: 30 mol\% $\mathrm{PbO}, 30$ mol\% $\mathrm{B}_{2} \mathrm{O}_{3}, 20$ mol\% $\mathrm{SiO}_{2}$ and $20 \mathrm{~mol} \% \mathrm{ZnO}$, with a softening temperature of $590^{\circ} \mathrm{C}$ [12]. The other enamels E106 (30 mol\% PbO, 15 mol\% $\mathrm{B}_{2} \mathrm{O}_{3}, 50 \mathrm{~mol} \% \mathrm{SiO}_{2}$ and $5 \mathrm{~mol} \% \mathrm{ZnO}$ ), E122 (40 mol\% PbO, $10 \mathrm{~mol} \% \mathrm{~B}_{2} \mathrm{O}_{3}, 50$ mol\% $\mathrm{SiO}_{2}$ and $0 \mathrm{~mol} \% \mathrm{ZnO}$ ), and $\mathrm{E} 34$ (40 mol\% PbO, 20 mol\% $\mathrm{B}_{2} \mathrm{O}_{3}, 35 \mathrm{~mol} \% \mathrm{SiO}_{2}$ and 5 mol\% $\mathrm{ZnO}$ ), have softening temperatures of $617^{\circ} \mathrm{C}, 613^{\circ} \mathrm{C}$ and $583^{\circ} \mathrm{C}$, respectively. Modernist blown base glasses are of the soda-lime type (about $15 \% \mathrm{Na}_{2} \mathrm{O}, 15 \% \mathrm{CaO}$ and $70 \% \mathrm{SiO}_{2}$ ) (Table 4$)$ and have a glass transition temperature $-\log \eta(\mathrm{Pa} \cdot \mathrm{s})=12.5$ - of about $575^{\circ} \mathrm{C}$ and deformation temperature $-\log \eta(\mathrm{Pa} \cdot \mathrm{s})=10.5-$ of about $615^{\circ} \mathrm{C}$ [12]. The enamel has to be fired above the glass transition temperature of the base glass to ensure a good reactivity/diffusivity between them but below the deformation temperature of the base glass; this leads to a relative narrow firing temperature range.

Finally, the grisaille is a high lead glass $(\approx 71 \% \mathrm{PbO})$ to which iron oxide (haematite, $\mathrm{Fe}_{2} \mathrm{O}_{3}$ ) and manganese oxide particles (pyrolusite, $\mathrm{MnO}_{2}$ ) are added (Fig. 4). Although haematite particles are still the main crystalline compound after firing, the particles react to form bixbyite, $(\mathrm{Fe}, \mathrm{Mn})_{2} \mathrm{O}_{3}$, and jacobsite, $\mathrm{Fe}_{2} \mathrm{MnO}_{4}$, and with the lead oxide to form melanotekite, $\mathrm{Pb}_{2}(\mathrm{Fe}, \mathrm{Mn})_{2}\left(\mathrm{Si}_{2} \mathrm{O}_{7}\right) \mathrm{O}_{2}$ (Fig. $4 \mathrm{~B}$ and $4 \mathrm{C}$ ). $\mathrm{Mn}^{4+}$ is reduced, first to 
$\mathrm{Mn}^{3+}$ (in bixbyite and in the lead silicate) and finally to $\mathrm{Mn}^{2+}$ (in the spinel structure), although all the structures may accept mixed valences. The grisaille glassy phase is a typical high lead glass with eutectic composition (40 mol\% $\mathrm{PbO}$ ) melting temperature of $717^{\circ} \mathrm{C}$ [28] and a softening temperature of $686^{\circ} \mathrm{C}$ [12]. High lead glasses are characterised by a high refractive index, low viscosity, and a large variation in viscosity with temperature $[24,29]$. The grisaille does not show a layered structure with floating particles as the density of the particles (melanotekite, $5.7 \mathrm{~g} / \mathrm{cm}^{3}$, haematite, $5.3 \mathrm{~g} / \mathrm{cm}^{3}$ and bixbyite $5.1 \mathrm{~g} / \mathrm{cm}^{3}$ ) is comparable to those of the glass.

A so-called flux was also found in the workshop (Table 1). The flux is a high lead borosilicate glass, 60 mol\% $\mathrm{PbO}$, with $20 \mathrm{~mol} \% \mathrm{~B}_{2} \mathrm{O}_{3}, 20 \mathrm{~mol} \% \mathrm{SiO}_{2}$ and little $\mathrm{ZnO}$. Rigalt describes several recipes for enamels where the flux is mixed with the pigment [18]. The flux has a very low softening temperature of $477^{\circ} \mathrm{C}$ [12]. However, the composition of the flux is outside the limits of lead borosilicate glass solders, increasing the amount of $\mathrm{B}_{2} \mathrm{O}_{3}$ above $40 \mathrm{~mol} \%$ does not produce an increase in the more stable $\mathrm{BO}_{4}$ units $[13,25]$, the equilibrium between trigonal and tetrahedral metaborate is broken, and the glass becomes less stable and susceptible to water corrosion.

\subsection{The historical enamels}

The historical enamels produced by the Rigalt, Granell \& cia workshop are extremely thin and fragile due to atmospheric corrosion and consequently the chemical analysis (Table 4) were significantly impeded by interferences from the base glass. The purple enamel from Palau de Justicia (PJ1) (Fig. 6A) was found to contain very little lead, boron and zinc compared to the purple replicated enamels and contained about 2000 ppm Au, $1.78 \% \mathrm{SnO}_{2}$ and $\mathrm{Au} / \mathrm{Ag} \approx 2$, (Table 4) which corresponds well to the purple enamel E14. Minor amounts of chlorine and traces of phosphorous were also detected by LA-ICP-MS both in the base glass and in the enamel. The SEM-BSE images of the cross section confirm the presence of lead sulphate, $\mathrm{PbSO}_{4}$, filling the bubbles and cracks (Fig. 6B). The enamel has a high silica $\left(45 \% \mathrm{SiO}_{2}\right)$, low $\mathrm{PbO}(7 \% \mathrm{PbO})$ and $\mathrm{ZnO}$ (0.6 \% $\mathrm{ZnO}$ ) content and the presence of sulphur (boron cannot be determined by SEM-EDX). The total is very low, confirming the heavy alteration of the enamel chemistry which we will discuss later. A lead enriched enamel-base glass interface with 
about $28 \% \mathrm{PbO}, 7.5 \% \mathrm{Na}_{2} \mathrm{O}$ and $6 \% \mathrm{CaO}$, may also be lead depleted assuming that the original composition of the enamel was much higher in lead ( $53 \% \mathrm{PbO})$. The area covered by the grisaille shows the same type of alteration, the precipitation of $\mathrm{PbSO}_{4}$ in the cracks and bubbles (Fig. 6F, 6G). The purple enamel is surrounded by grisaille contour lines which are applied on the same side of the base glass (Fig. 6A). Although Lacroix in his treatise advised of applying the grisaille on the other side of the base glass to avoid enamel and grisaille mix, the application of the enamels on the same side as the contour grisaille was not uncommon. Rigalt disregarded the advice because of the mismatch between the contour lines and the enamel paint produced by the thickness of the base glass. Rigalt also noted that besides some difficulties, the result was more satisfactory [18].

The grisaille particles, iron rich spinel containing manganese and copper $\left(\mathrm{Fe},(\mathrm{Mn}, \mathrm{Cu}) \mathrm{O}_{4}\right)$ and iron rich lead silicate $\left(\mathrm{Pb}_{2}(\mathrm{Fe}, \mathrm{Mn})_{2}\left(\mathrm{Si}_{2} \mathrm{O}_{7}\right) \mathrm{O}_{2}\right)$ (Fig. 6H) appear mixed with the purple enamel. The presence of an iron rich spinel with copper instead of haematite as found in the workshop grisaille must be related to the addition of copper oxide. The addition of copper to the grisailles was very common [30]; its main purpose is to reduce the amount of haematite formed to suppress the red hue. Gypsum, $\mathrm{CaSO}_{4} \cdot 2 \mathrm{H}_{2} \mathrm{O}$, was also found deposited on the surface.

The enamelled glass from the Seu del Districte Sants-Montjuic has a blue enamel over a yellow base glass with a grisaille mixed with the enamel in some areas (SM1) (Fig. 7A). The blue enamel contains $\mathrm{Al}, \mathrm{Cr}$ and $\mathrm{Co}$ and some Fe which are related to the presence of pigment particles of the type $(\mathrm{Al}, \mathrm{Cr})_{2} \mathrm{CoO}_{4}$ (Fig. 7B and 7D) like in enamel E34. While E34 also contains copper which gave a green tinge to the enamel, no copper was detected in SM1, which in fact is blue. Minor amounts of chlorine and traces of phosphorous were identified both in the base glass and in the enamel. The enamel shows also a lead enriched enamel-base glass interface ( $37 \% \mathrm{PbO}) . \mu$-XRD patterns obtained from an area with grisaille and enamel (Fig. 7D) show from interface to surface the presence of the blue cochromite particles, then the iron rich spinel $\left(\mathrm{Fe},(\mathrm{Mn}, \mathrm{Cu}) \mathrm{O}_{4}\right)$, tenorite $(\mathrm{CuO})$ and melanotekite $\left(\mathrm{Pb}_{2}(\mathrm{Fe}, \mathrm{Mn})_{2}\left(\mathrm{Si}_{2} \mathrm{O}_{7}\right) \mathrm{O}_{2}\right)$ related to the grisaille and calcium carbonate (calcite, $\mathrm{CaCO}_{3}$ ) and basic lead carbonate (hydrocerussite, $\mathrm{Pb}_{3}\left(\mathrm{CO}_{3}\right)_{2} \cdot(\mathrm{OH})_{2}$ ) related to pollution and alteration. Other areas of the 
surface show the blue enamel particles on top of the grisaille particles (Fig. 7E and Fig. 7F).

The UV-Vis, NIR spectra and the colour coordinates were also measured and are shown in Fig. 8 and Table 5 respectively. The absorbance of the purple enamel (PJ1) shows the absorption band associated with $\mathrm{Ag}-\mathrm{Au}^{\circ}$ alloy nanoparticles. The absorbance measured in transmission mode of the blue enamel (SM1) is dominated by the colour of the base glass, which is yellow; on the contrary, the Reflectance spectrum, Fig. 8 shows the triple absorption band between $500 \mathrm{~nm}$ and $650 \mathrm{~nm}$ and also the large NIR absorption between $1250 \mathrm{~nm}$ and $1750 \mathrm{~nm}$ related to tetrahedral $\mathrm{Co}^{2+}$. Comparing the historical enamels from the Rigalt, Granell \& cia workshop with the new replica enamels, the former show lower colour saturation, most probably related to the presence of lead and calcium sulphate or carbonate precipitates which are white.

The yellow and green enamels produced by the Maumejan workshop in Barcelona, and found in the Estació del Nord are fully amorphous and show no chemical alteration (Table 4). The grisaille is applied on the opposite side of the base glass, and appears also mainly unaltered. Both enamels are made of a high lead zinc borosilicate glass not very different from the replica enamels from the Rigalt \& Granell workshop. The yellow enamel shows the characteristic $\mathrm{Cr}^{6+} \mathrm{UV}$ absorption band and the green enamel also the broad absorption band with a maximum at $800 \mathrm{~nm}$ related to $\mathrm{Cu}^{2+}$ (Fig. 8). The good preservation state might be related to the fact that the enamelled glass was part of a panel which has always been indoors. Nevertheless, the workshop was characterised by its solid technique although the stained glasses produced were not of a high artistic quality compared to other workshops.

\subsection{Alteration of the historical enamels}

The historical enamels from the Rigalt, Granell \& cia workshop appear depleted in $\mathrm{Pb}$, $\mathrm{B}$ and $\mathrm{Zn}$, enriched in $\mathrm{Si}, \mathrm{Ca}$ and $\mathrm{Na}$, and show the precipitation of lead and calcium sulphate or carbonate within the cracks, bubbles and on the surface. Lead sulphate (anglesite, $\mathrm{PbSO}_{4}$ ) and calcium sulphate dihydrate (gypsum, $\mathrm{CaSO}_{4} \cdot 2 \mathrm{H}_{2} \mathrm{O}$ ) are found in PJ1, while basic lead carbonate (hydrocerussite, $\mathrm{Pb}_{3}\left(\mathrm{CO}_{3}\right)_{2} \cdot(\mathrm{OH})_{2}$ ) and calcium carbonate (calcite, $\mathrm{CaCO}_{3}$ ) are found in $\mathrm{SM} 1$. The difference between the crystalline 
precipitates is related to the atmosphere of the environment, the pollutants of the city in the former and a suburb district in the latter. Lead leaching from the enamel in presence of humidity and of atmospheric gases/pollutants $\left(\mathrm{SO}_{2}\right.$ and $\left.\mathrm{CO}_{2}\right)$ results in the subsequent precipitation of lead and calcium sulphates and carbonates [31]. Consequently, the corrosion is humidity-dependent as water provides the medium for the dissolution of the glass and dissolution/deposition of atmospheric gases. Humidity is in any case the principal activator of the whole corrosion process, it is not necessary to have a very humid environment to initiate the process. Minor amounts of chlorine and traces of phosphorous were also detected by LA-ICP-MS. The presence of chlorine is related to the proximity to the sea shore and the presence of phosphorous to bird droppings.

Aqueous corrosion in soda and soda-lime borosilicate glasses is based in a glass dissolution-silica precipitation reaction which involves a complex process. The process is controlled by a diffusion-controlled ion exchange front, involving the inward diffusion of $\mathrm{H}^{+}$(and $\mathrm{K}^{+}$and $\mathrm{Ca}^{2+}$ ) coupled to an outward diffusion of $\mathrm{Na}^{+}\left(\right.$and $\mathrm{Ca}^{2+}$ ) and B. The surface altered layer formed is composed of a so called 'hydrated glass' depleted in alkaline elements and an amorphous layer of porous, silica-rich material (often called 'gel'), and, in some cases, by precipitates of secondary insoluble phases. $[32,33]$ In a lead glass, neutral and acidic media corrosion involves also an interdiffusion controlled lead leaching and silica dissolution and reprecipitation $[34,35]$. Boron is highly soluble while on the contrary, calcium and lead carbonates or sulphates are highly insoluble.

$\mathrm{SO}_{2}$ enters the liquid phase by gaseous transport, while $\mathrm{SO}_{4}{ }^{2-}$ enters from deposited atmospheric particles dissolved in rain water. Carbon dioxide is an abundant atmospheric gas, and dissolved in water produces carbonates and basic carbonates where more aggressive competing ions are not present. Nevertheless, organic acid vapours common in urban atmospheres and in rain water are also highly aggressive [31]. Atmospheric nitrate aerosol particles or $\mathrm{NO}_{2}$ gases are likely to produce nitric acid in rain water, which although being highly aggressive are not expected to produce solid precipitates as both lead and calcium nitrates are highly soluble. 
The kinetics of reaction of the glass surface have been determined in the literature for historical glasses [36] and in particular for potash-lime silicate [37], lead-potash silicate [37], soda and soda-lime borosilicate [32,33] and lead-silicate glasses [34,35] in laboratory corroding conditions. Leached depths for $\mathrm{K}^{+}$and $\mathrm{Ca}^{2+}$ vary between 1.1 and $1.2 \mu \mathrm{m}$ for exposure times of up to six years, and syngenite $\left(\mathrm{K}_{2} \mathrm{SO}_{4} \cdot \mathrm{CaSO}_{4} \cdot \mathrm{H}_{2} \mathrm{O}\right)$ and gypsum $\left(\mathrm{CaSO}_{4} \cdot 2 \mathrm{H}_{2} \mathrm{O}\right)$ are formed in sheltered conditions [37]. Alkaline leaching and formation of lead carbonate precipitates was determined in lead-potash silicate enamels after 2 months of exposure. For lead-silicate glasses typical leached thicknesses of 1-2 $\mu \mathrm{m}[34,35]$ are found after only $162 \mathrm{~h}$ exposure although interdiffusion is expected to slow down the process in long term corrosion [33]. Considering the thickness of our enamels $(10-50 \mu \mathrm{m})$ the corrosion layer might build up in a relatively short period (months to few years) after a continuous exposure. Dry and humid periods and temperature variations will determine the speed of degradation of the glass surface.

Consequently, atmospheric corrosion is fully consistent with the degradation observed in our historical enamels and grisailles. The composition of the enamels, crystalline precipitates and degree of affectation after one hundred years depends on the humiddry cycle and atmospheric gases and pollutants. Temperature variations will also promote the formation of cracks and favour the solubility/recrystallization cycle of some alteration compounds (of particular importance for calcium sulphate). Moreover, grisaille and enamels appear mixed in many areas of the painted surface. The application of the enamels on the same side as the grisaille is a bad practice as the mixing of enamels and grisailles may result in a material of reduced stability.

Our results show that the chemical composition and microstructure of the enamels from the workshop are heavily altered independently of their colour and composition and that the alteration follows the characteristic water induced atmospheric corrosion pattern. Nevertheless, some differences found in the microstructures of the replica enamels may explain the reason why blue and green enamels may show flaking and losses more often than the other coloured enamels. The enamels containing pigment particles with a lower density than the glassy matrix show a typical layered structure (Fig. 3) with the particles floating in a lead poorer glass over a lead rich ( $50 \% \mathrm{PbO})$ 
enamel-base glass reaction layer. This layered microstructure is found in the green and blue enamels that contain cobalt aluminate and cobalt and chromium aluminate pigment particles (blue, E33, and green, E34, enamels) and is not found in any of the other enamels where the particles are denser, or contain transition metal ions dissolved in the glass. The leakage of lead will affect the stability of these enamels more drastically and rapidly advancing the surface flaking.

Consequently, the data obtained shows why the nature of the pigment particles, colourants and microstructure of the blue and green enamels and grisailles (an opaque glassy paint used to draw contours and give artistic effects) makes them more prone to degradation with respect to other colour enamels.

Another source of instability is the greater absorption in the near infrared region, between $1200 \mathrm{~nm}$ and $1750 \mathrm{~nm}$ (Fig. 5B) that the blue cobalt centres ( $\left.\mathrm{CoO}_{4}\right)$ show; an effect which is more dramatic when the enamel contains cobalt aluminate particles, Fig. 5B. Copper green glasses show also a near total light absorption at $800 \mathrm{~nm}$ which extends to the infrared (up to $1000 \mathrm{~nm}$ ) (Fig. 5B) [17]. Grisailles contain copper and sometimes cobalt dissolved in the glass and/or forming crystalline compounds to reduce the red hue caused by the presence of $\mathrm{Fe}_{2} \mathrm{O}_{3}$, although we do not have detailed information of the absorption of infrared light by the various types of particles present in the grisailles, the presence of $\mathrm{Fe}^{2+}$ and $\mathrm{Co}^{2+}$ or $\mathrm{Cu}^{2+}$ suggests also and enhanced absorbance in the NIR. This enhanced absorbance will produce an increase in the overall temperature of the enamel and also a thermal mismatch between particles, enamel glass and base glass. The differences in the thermal expansion coefficients between particles/enamel glass and between the enamel and the base glass are expected to give rise to the formation of cracks

Finally, supporting our data, recent studies using Infrared Thermography have shown that dark enamels and grisailles show an increase of the temperature $40 \%$ higher than those of the transparent glass [38,39] and about 20\% higher than other colour enamels. 


\section{Conclusions}

The enamels used by the Rigalt, Granell \& cia modernist workshop have been replicated, analysed and their chemical composition, pigment particles, colourants and microstructure determined. The enamels are made of a lead-zinc borosilicate glass (30$40 \% \mathrm{PbO}, 0-15 \% \mathrm{ZnO}, 15-19 \% \mathrm{~B}_{2} \mathrm{O}_{3}$ ) mixed with a wide variety of colourants and pigment particles. The enamel glass is characterised by a low sintering temperature and softening point while keeping a reasonable stability against chemical corrosion, in particular to water corrosion.

The chemical composition of the glassy phase of the blue and green enamels is not different from those found in the other colour enamels. Nevertheless, the study has revealed that the blue and green enamels containing cobalt and cobalt chromium aluminate particles show a layered microstructure of heterogeneous chemistry across the enamel, with a lead depleted layer with pigment particles floating near the surface and a lead enriched interface at the base glass. This particular microstructure is due to the lower density of the pigment particles compared to those of the glassy matrix. This heterogeneity is expected to be in part responsible for the enhanced flaking of the enamels exposed to weathering. Moreover, blue and green enamels containing cobalt, either forming cobalt or cobalt-chromium aluminate particles or dissolved in the glass, as well as copper dissolved in the glass, show an enhanced absorbance in the Near Infrared. The enhanced absorbance of particles and colour centres in the enamel would be responsible for the increase in the overall temperature of the enamel submitted to solar irradiation, as well as for the thermal mismatch between pigment particles, enamel glass and base glass. Thermal stresses will cause the formation of cracks due to the mismatch in the thermal expansion coefficients, and a faster/greater deterioration of the enamels.

The analysis of the historical enamels produced by the Rigalt, Granell \& cia. workshop in the first decade of the $20^{\text {th }}$ century shows that the whole thickness of the enamels is affected by atmospheric corrosion. The enamels show an important lead loss, the formation of a silica-rich glass and the crystallisation of sulphates and/or carbonates of 
lead and calcium in cracks and bubbles. This corrosion is observed in all the enamels studied independently of the colour, although the crystalline corrosion products found differ depending on the composition of the atmosphere. Moreover, some technical characteristics of the Rigalt, Granell \& cia. enamels, in particular the application of the enamels and grisaille on the same side of the base glass, and the mixture of grisaille and colour enamels to enhance the opacity (which was desirable to reduce the transmission of light in buildings with Mediterranean climate) and to give some artistic effects, increases the instability of the enamels to atmospheric corrosion. This could also explain the multiple conservation problems shown by the enamels produced by Rigalt, Granell \& cia. compared to other workshops from the period.

Our results demonstrated that in order to improve the conservation of the enamelled window glass, a protection from humidity and atmospheric gasses should also be accompanied by a filter of infrared light, of particular importance in Mediterranean climates.

\section{Acknowledgements}

We are grateful to the funds received from Ministerio de Ciencia e Innovación (Spain) project MAT2016-N0748719-R and Generalitat de Catalunya project 2017 SGR 00042. We are particularly grateful to Jordi Bonet from J.M. Bonet Vitralls S.L. who kindly supplied all the materials from the Rigalt, Granell \& cia workshop as well as historic enamelled glasses. The SR- $\mu$-XRD measurements were performed at BM4-MSPD beamline at Alba synchrotron facility with the collaboration of Alba staff. 


\section{References}

[1] A. Thomas, Le Vitrail a l'Exposition Universelle (Stain glass in the Universal Exhibition), in: L'Art Décorative, París, 1900, pp. 179 -187.

[2] N. Gil Farré, El taller de vitralls modernista Rigalt, Granell \& Cia. (1890-1931) (The Modernist stain glass workshop of Rigalt, Granell \& Co. (1890-1931)), phD thesis, Universitat de Barcelona, Barcelona, 2013.

[3] A. Lacroix, Des couleurs vitrifiables et de leur employ pour la peinture sur porcelain, faience, vitraux (About the glassy colours and their use for the painting on porcelain, faience, stain glass), Chez A. Lacroix, Paris, 1872.

[4] Grace's guide to British Industrial History. https://www.gracesguide.co.uk/

[5] O. Schalm, V. Van der Linden, P. Frederickx, S. Luyten, G. Van der Snickt, J. Caen, D. Schryvers, et al., Enamels in stained glass Windows: Preparation, chemical composition, microstructure and causes of deterioration. Spectrochim. Acta B 64 (2009) 812-820.

[6] G. Van der Snikt, O. Schalm, J. Caen, K. Janessens, M. Schreiner, Blue enamel on sixteenth and seventeenth-century window glass: deterioration, microstructure, composition and preparation, Stud. Conserv. 51(3) (2006) 212-222.

[7] N. Attard-Montalto, A. Shortland, $17^{\text {th }}$ century blue enamel on window glass from the cathedral of Christ Church, Oxford: Investigating its deterioration mechanism, J. Cult. Herit. 16 (2015) 365-371.

[8] F.S. Barff, Silicates, silicides, glass and glass painting, J. Soc. of Arts. 20 (1034) (1872) 841-852.

[9] A. Machado, M. Vilarigues, Blue enamel pigment-Chemical and morphological characterization of its corrosion process. Corros. Sci. 139 (2018) 235-242.

[10] L. Robinet, M. Spring, S. Pagès-Camagna, D. Vantelon, N. Trcera, Investigation of the Discoloration of Smalt Pigment in Historic Paintings by Micro-X-ray Absorption Spectroscopy at the Co K-Edge. Anal. Chem. 83(13) (2011) 5145-5152. 
[11] A. Gilchrist, The tears wept by our windows: sever paint loss from stained glass windows of the Mid-Nineteenth Century, Vidimus, 64 (2012).

[12] M. Beltrán, F. Brock, T. Pradell, Thermal properties and stability of Catalan Modernist blue and green enamels. Int. J. Appl. Glass Sci. 10 (2019) 414-425.

[13] Petrovskaya TS. Properties of lead borosilicate glasses: The effect of the structure. Glass Ceram. 54(11-12) (1997) 347-350.

[14] B. Gratuze, J. Blet-Lemarquand, J.N. Barrandon, Mass Spectrometry with laser sampling: A new tool to characterize Archaeological materials, J. Radioanal. Nucl. Chem. 247 (2001) 645-656.

[15] F. Fauth, I. Peral, C. Popescu, M. Knapp, The new material science powder diffraction beamline at ALBA synchrotron, Powder Diffr. 28 (2013) 360-S370.

[16] D. Mahl, J. Diendorf, S. Ristig, C. Greulich, Z.A. Li, M. Farle, M. Köller, M. Epple, Silver, gold, and alloyed silver-gold nanoparticles: characterization and comparative cell-biologic action, J. Nanopart. Res. 14 (2012) 1153-1155.

[17] W.A. Weyl, Coloured glasses, Society of Glass Technology, Sheffield, 2016.

[18] J. Vila-grau, F. Rodon, Els vitrallers de la Barcelona Modernista, Edicions Polígrafa S.A., Barcelona, 1982, pp. 178-180.

[19] M.W. Murphy, Y.M. Yiu, M.J. Ward, L. Liu, Y. Hu, J.A. Zapien, Y.K. Liu, T.K. Sham,

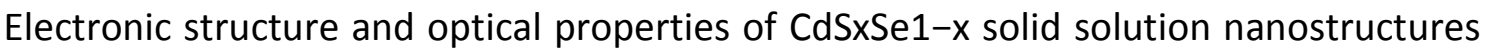
from X-ray absorption near edge structure, X-ray excited optical luminescence, and density functional theory investigations, J. App. Phys. 116 (2014) 193709.

[20] O. Villain, G. Calas, L. Galoisy, L. Cormier. XANES determination of chromium oxidation states in glasses: comparison with optical absorption spectroscopy, J. Am. Ceram. Soc. 90(11) (2007) 3578-3581. 
[21] G. Molina, G.P. Odin, T. Pradell, A.J. Shortland, M.S. Tite, Production technology and replication of lead antimonate yellow glass from New Kingdom Egypt and the Roman Empire, J. Archaeol. Sci. 41 (2014) 171-184.

[22] W. Zheng, J. Zou, Synthesis and characterization of blue TiO2/CoAl2O4 complex pigments with good colour and enhanced near-infrared reflectance properties, RSC Advances 5(107) (2015) 87932.

[23] M. Ookawa, T. Sakurai, S. Mogi, T. Yokokawa, Optical spectroscopic study of lead silicate glasses doped heavily with iron oxide. Mater. Trans.-JIM 38 (1997) 220-225. (see pp. 60 and 99)

[24] W. Vogel, Glass chemistry, Springer Verlag, Berlin, 1992.

[25] M.P. Brungs, E.R. Cartney, Structure of sodium borosilicate glasses, Phys. Chem. Glasses 16 (1975) 48-52.

[26] D. Möncke, G. Tricot, A. Winterstein-Beckmann, L. Wondraczek, E.I. Kamitsos, On the connectivity of borate tetrahedra in borate and borosilicate glasses, Phys. Chem. Glasses 56(5) (2015) 203-211.

[27] J.M. Wu, H.L. Huang, Microwave properties of zinc, barium and lead borosilicate glasses, J. Non-Cryst. Solids 260 (1999) 116-124.

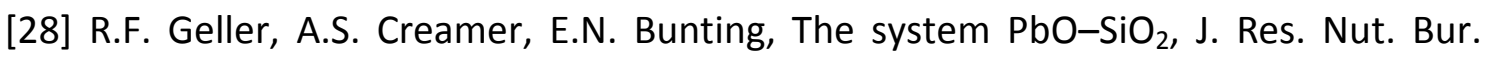
Stand. 13 (1934) 237-244.

[29] S. Kohara, H. Ohno, M. Takata, T. Usuki, H. Morita, K. Suzuya, et al., Lead silicate glasses: Binary network-former glasses with large amounts of free volume, Phys. Rev. B. $82(2010) 134209$.

[30] T. Pradell, G. Molina, S. Murcia, R. Ibañez, C. Liu, J. Molera, A.J. Shortland, Materials, Techniques, and Conservation of Historic Stained Glass "Grisailles", Int. J. Appl. Glass Sci. 7(1) (2016) 41-58.

[31] T.E. Graedel, Chemical mechanisms for the atmospheric corrosion of lead, J. Electrochem. Soc. 141(4) (1994) 922-927. 
[32] T. Geisler, T.J. Nagel, M.R. Kilburn, A. Janssen, J.P. Icenhauer, R.O.C. Fonseca, M. Grange, A.A. Nemchin, The mechanism of borosilicate glass corrosion revisited, Geochim. Cosmochim. Acta 158 (2015) 112-129.

[33] C. Lenting, O. Plümper, M. Kilburn, P. Guagliardo, M. Klinkenberg, T. Geisler, Towards a unifying mechanistic model for silicate glass corrosion, npj Materials Degradation 2(1) 28 (2018).

[34] S. Wood, J.R. Blachere, Corrosion of Lead Glasses in Acid Media: I, Leaching Kinetics. J. Amer. Ceram. Soc. 61(7-8) (1978) 287-292.

[35] S. Wood, J.R. Blachere, Corrosion of Lead Glasses in Acid Media: II, Concentration profile measurements, J. Amer. Ceram. Soc. 61(7-8) (1978) 292-297.

[36] J. Sterpenich, G. Libourel, Using stained glass windows to understand the durability of toxic waste matrices, Chem. Geol. 174 (2001) 181-193.

[37] M. Melcher, M. Schreiner, Evaluation procedure for leaching studies on naturally weathered potash-lime-silica glasses with medieval composition by scanning electron microscopy, J. Non-Crystall. Sol. 351(14-15) (2001) 1210-1225.

[38] T. Palomar, F. Agua, M. Gómez-Heras, Comparative assessment of stained-glass windows materials by infrared thermography, Int. J. Appl. Glass Sci. 9 (2018) 530-539.

[39] T. Palomar, M. Silva, M. Vilarigues, I. Pombo Cardoso and D. Giovannacci, Impact of solar radiation and environmental temperature on Art Nouveau glass windows, Herit. Sci. 7 (2019) 82 


\section{Table captions}

Table 1. Chemical composition of the replica enamels produced obtained of the enamels produced from the raw materials found in the Rigalt i Granell workshop determined by LA-ICP-MS. Sulphur was not measured.

Table 2. Crystalline compounds determined in the powder and in the enamels. The Xray Diffraction JCPDS-PDF numbers used for the identification of the compounds are given in square brackets.

Table 3. Lab* colour coordinates calculated from the Diffuse Reflectance spectra obtained of the replica enamels from the Rigalt i Granell workshop.

Table 4. LA-ICP-MS data of the historical base glasses and enamels from Palau de Justicia and from the Seu del Districte de Sants-Montjuic (Rigalt i Granell) as well as from the Estació del Nord (Maumejan)

Table 5. Lab* colour coordinates calculated from the Diffuse Reflectance spectra obtained of the historical enamels.

\section{Figure captions}

Fig. 1. Image of a Modernist stained glass from Museu d'Art de Cerdanyola by L. Dietrich, 1888-1910, showing the characteristic green and blue enamels decay (co. Jordi Bonet).

Fig. 2. (A) SEM-BSE image from the purple enamel E14 and (B) SEM-BSE image from a FIB polished surface of the purple enamel showing the presence of small Au-Ag-Sn nanoparticles of various compositions. (C) SEM-BSE image and (D) $\mu$-XRD pattern from the red enamel E23 showing the presence of $\mathrm{CdS}_{x} \mathrm{Se}_{1-x}$ [P63mc with $\mathrm{a}=4.19 \mathrm{c}=6.82$ ] and, CdS [01-075-1545], CdSe [01-088-2346], $\mathrm{ZnO}$ [01-079-0206] and $\mathrm{SnO}_{2}$ [01-0710652] particles. (E) SEM-BSE image and (F) $\mu$-XRD pattern from the red enamel E25 showing the presence of $\mathrm{Pb}_{2} \mathrm{O}\left(\mathrm{CrO}_{4}\right)$ [01-076-0861] and $\mathrm{SnO}_{2}$ [01-071-0652] particles.

Fig. 3. (A) and (B) SEM-BSE images from the yellow enamel E4 and the green enamel E34 respectively showing the absence of any crystalline particle in the former and of $\mathrm{Co}(\mathrm{Cr}, \mathrm{Al}) \mathrm{O}_{4}$ and $\mathrm{Pb}_{2}(\mathrm{Sn}, \mathrm{Sb})_{2} \mathrm{O}_{7}$, particles in the later. (C) and (D) SEM-BSE image and SEM-EDS chemical analysis of the cross section from the blue enamel E33 showing the presence of $\mathrm{Al}_{2} \mathrm{CoO}_{4}$ particles. 
Figure 4. (A) and (B) SEM-BSE images and (C) $\mu$-XRD pattern from the grisaille G1, showing the presence of $\mathrm{Fe}_{2} \mathrm{O}_{3}$ [01-072-0469], $(\mathrm{Fe}, \mathrm{Mn})_{2} \mathrm{O}_{3}$ [01-071-0636], $\mathrm{FeMn}_{2} \mathrm{O}_{4}$ [01-075-0035] and $\mathrm{Pb}_{2}(\mathrm{Fe}, \mathrm{Mn})_{2} \mathrm{Si}_{2} \mathrm{O}_{9}$ [01-088-1889] crystallites. Melanotekite is seen as white precipitates around the darker grey iron oxide particles in the SEM-BSE image

Fig. 5. (A) UV-Vis spectra taken in transmission mode $-\log (1 / T)$ - from the enamels and showing the chromophores, $\mathrm{Cr}^{6+}$ in the yellow enamels $\mathrm{E} 3, \mathrm{E} 4$ and $\mathrm{E} 106, \mathrm{Mn}^{3+}$ in the red enamel E124, and $\mathrm{Cu}^{2+}$ in the green enamel E89, of $\mathrm{Ag}-\mathrm{Au}^{\circ}$ nanoparticles in the purple enamels E14 and E107, the ultraviolet absorption of the CdS and (Cd,Se)S nanoparticles in the red enamel E25 and the absorption bands characteristic of, cobalt and copper and of $\mathrm{Co}(\mathrm{Cr}, \mathrm{Al}) \mathrm{O}_{4}$ and $\mathrm{Al}_{2} \mathrm{CoO}_{4}$ particles in the green and blue enamels. $\mathrm{Fe}^{3+}$ absorption bands are also seen but are related to the base glass. (B) NIR Absorption spectra showing the enhanced absorption shown by cobalt (E115, E122), cobalt-chromium (E121) and cuprous (E89) ions dissolved in the glass and by $\mathrm{Al}_{2} \mathrm{CoO}_{4}$ (E33, E114) and $\mathrm{Co}(\mathrm{Cr}, \mathrm{Al}) \mathrm{O}_{4}$ particles (E34). The absorbance between $1000 \mathrm{~nm}$ and $1500 \mathrm{~nm}$ of the base glass is related to $\mathrm{Fe}^{2+}$.

Fig. 6. (A) Purple enamel with some contour grisaille over a transparent glass fragment from the Palau de Justicia (PJ1) by Rigalt \& Granell; SEM-BSE images (B) showing the presence of large bubbles and cracks filled with $\mathrm{PbSO}_{4},(\mathrm{C})$ three layers $\mathrm{A} 1$ showing the suspension of gold-silver-tin particles, A2 corresponding to the reaction of the enamel glass with the base glass and $A 3$ the base glass and (D) the suspension gold-silver-tin particles. (E) SEM-EDS analysis of the three layers. (F) and (G) SEM-BSE images of the contour grisaille showing the presence of bubbles and cracks filled with $\mathrm{PbSO}_{4}$ and $(\mathrm{H})$ $\mu$-XRD patterns of the grisaille taken near the surface and the base glass respectively; $\mathrm{PbSO}_{4}$ [01-082-1855], $\mathrm{CaSO}_{4} \cdot 2 \mathrm{H}_{2} \mathrm{O}$ [01-074-1905], $\mathrm{FeMn}_{2} \mathrm{O}_{4}$ [01-075-0035] and $\mathrm{Pb}_{2}(\mathrm{Fe}, \mathrm{Mn})_{2} \mathrm{Si}_{2} \mathrm{O}_{9}[01-088-1889]$.

Fig. 7. (A) Blue enamel mixed with grisaille over a yellow glass fragment from the Seu del Districte Sants-Montjuic (SM1) by Rigalt \& Granell; (B) SEM-BSE image showing the presence of particles of $(\mathrm{Al}, \mathrm{Cr})_{2} \mathrm{CoO}_{4}$ from the blue enamel and of $\mathrm{Pb}_{2}(\mathrm{Mn}, \mathrm{Fe})_{2} \mathrm{Si}_{2} \mathrm{O}_{9}$ from the grisaille and also the enamel-base glass interaction layer (A1); (C) SEM-EDS analysis of the enamel-glass interaction layer and (D) $\mu$-XRD patterns obtained across 
the enamel layer showing the enamel and grisaille particles, $(\mathrm{Al}, \mathrm{Cr})_{2} \mathrm{CoO}_{4}[\mathrm{Fd}-3 \mathrm{~m}$, $\mathrm{a}=8.333 \AA$ ],$(\mathrm{Fe}, \mathrm{Mn})_{2} \mathrm{CuO}_{4}\left[\mathrm{Fd}-3 \mathrm{~m}, \mathrm{a}=8.266 \AA\right.$ ], $\mathrm{CuO}$ [01-072-0629] and $\mathrm{Pb}_{2}(\mathrm{Fe}, \mathrm{Mn})_{2} \mathrm{Si}_{2} \mathrm{O}_{9}$ [01-088-1889], and also the presence of $\mathrm{CaCO}_{3}$ [01-083-0577] and $\mathrm{Pb}_{2}\left(\mathrm{CO}_{3}\right)_{2}(\mathrm{OH})_{2}[00-$ 013-0131] compounds on the surface. (E) Bright field optical Microscope and (F) SEMBSE images showing also particles from the grisaille and from the blue enamel on the top.

Fig. 8. (A) UV-Vis and (B) NIR spectra taken in transmission mode from the purple (PJ1) and yellow and green enamels (EN1) and taken in Reflection mode from the blue enamel (SM1). 
Table 1. Chemical composition of the replica enamels produced obtained of the enamels produced from the raw materials found in the Rigalt $i$ Granell workshop determined by LA-ICP-MS. Sulphur was not measured. T: Transparent, O: Opaque

\begin{tabular}{|c|c|c|c|c|c|c|c|c|c|c|c|c|c|c|c|c|c|c|c|c|c|c|c|c|}
\hline \multirow{2}{*}{ Color } & \multirow{2}{*}{ Sample } & \multirow{2}{*}{ Opacity } & \multirow{2}{*}{ Manufacturer } & \multicolumn{16}{|l|}{$w t \%$} & \multicolumn{5}{|c|}{$\mathrm{ppm}$} \\
\hline & & & & $\mathrm{B}_{2} \mathrm{O}_{3}$ & $\mathrm{SiO}_{2}$ & Zno & $\mathrm{PbO}$ & $\mathrm{Na}_{2} \mathrm{O}$ & $\mathrm{MgO}$ & $\mathrm{Al}_{2} \mathrm{O}_{3}$ & $\mathrm{~K}_{2} \mathrm{O}$ & $\mathrm{CaO}$ & $\mathrm{Cr}_{2} \mathrm{O}_{3}$ & $\mathrm{MnO}$ & $\mathrm{Fe}_{2} \mathrm{O}_{3}$ & $\mathrm{CoO}$ & $\mathrm{CuO}$ & $\mathrm{SnO}_{2}$ & $\mathrm{Sb}_{2} \mathrm{O}_{5}$ & $\mathrm{Se}$ & $\mathrm{Cd}$ & $\mathrm{Ni}$ & $\mathrm{Ag}$ & $\mathrm{Au}$ \\
\hline \multirow{2}{*}{ Purple } & E14 & $\mathrm{T}$ & \multirow{2}{*}{ Lacroix } & 21.05 & 8.64 & 11.15 & 53.23 & 2.09 & 0.09 & 0.30 & 0.18 & 0.86 & 0.01 & 0.01 & 0.11 & 0.03 & 0.00 & 1.78 & 0.04 & & & & 1112 & 2117 \\
\hline & E107 & $1 / 20$ & & 19.80 & 8.93 & 13.82 & 52.62 & 0.91 & 0.02 & 0.24 & 0.26 & 0.61 & 0.00 & 0.00 & 0.05 & 0.00 & 0.00 & 2.60 & 0.01 & & & & 19 & 82 \\
\hline \multirow{3}{*}{ Red } & E23 & $1 / 20$ & \multirow{3}{*}{ Lacroix } & 16.55 & 9.25 & 14.03 & 40.82 & 0.78 & 0.00 & 0.26 & 0.08 & 0.55 & 0.00 & 0.00 & 0.03 & 0.00 & 0.00 & 7.58 & 0.01 & 1.95 & 7.97 & 19 & & \\
\hline & E25 & $\mathrm{T}$ & & 12.12 & 7.86 & 9.94 & 62.67 & 0.40 & 0.01 & 0.41 & 0.18 & 0.38 & 3.53 & 0.00 & 0.13 & 0.00 & 0.00 & 2.29 & 0.01 & & & & & \\
\hline & E124 & $\mathrm{T}$ & & 17.81 & 7.54 & 13.69 & 56.67 & 1.35 & 0.16 & 0.47 & 0.13 & 0.73 & 0.00 & 1.24 & 0.08 & 0.00 & 0.01 & 0.03 & 0.03 & & & 10 & & \\
\hline \multirow{4}{*}{ Yellow } & E3 & $T$ & \multirow{4}{*}{ Lacroix } & 6.97 & 30.41 & 0.02 & 52.97 & 5.06 & 0.06 & 0.27 & 0.11 & 2.61 & 1.25 & 0.00 & 0.10 & 0.00 & 0.00 & 0.01 & 0.03 & & & & & \\
\hline & E4 & $\mathrm{T}$ & & 16.17 & 7.23 & 13.75 & 59.44 & 0.95 & 0.04 & 0.54 & 0.18 & 0.42 & 0.47 & 0.64 & 0.08 & 0.00 & 0.01 & 0.00 & 0.00 & & & & & \\
\hline & E106 & $1 / 20$ & & 7.87 & 22.38 & 4.09 & 54.61 & 2.10 & 0.04 & 4.80 & 0.41 & 0.45 & 0.01 & 0.00 & 0.23 & 0.00 & 0.00 & 0.49 & 2.41 & & & 10 & & \\
\hline & E119 & $1 / 20$ & & 20.35 & 8.19 & 13.88 & 53.40 & 1.11 & 0.00 & 0.23 & 0.25 & 0.47 & 0.52 & 0.00 & 0.05 & 0.00 & 0.00 & 1.43 & 0.01 & & & & & \\
\hline \multirow{3}{*}{ Green } & E34 & $1 / 20$ & \multirow{3}{*}{ Lacroix } & 8.13 & 10.74 & 1.85 & 49.82 & 2.04 & 0.40 & 5.92 & 0.50 & 0.33 & 10.84 & 0.01 & 0.20 & 6.47 & 0.27 & 0.91 & 1.23 & & & 1269 & & \\
\hline & E89 & $T$ & & 16.36 & 8.49 & 12.37 & 53.94 & 1.73 & 0.02 & 0.45 & 0.21 & 0.66 & 0.16 & 0.01 & 0.16 & 0.00 & 5.32 & 0.06 & 0.01 & & & 18 & & \\
\hline & E121 & $T$ & & 15.24 & 6.90 & 13.94 & 59.23 & 0.87 & 0.04 & 0.52 & 0.17 & 0.50 & 0.37 & 0.00 & 0.06 & 2.01 & 0.01 & 0.01 & 0.07 & & & 290 & & \\
\hline \multirow{4}{*}{ Blue } & E33 & $T$ & Wengers & 11.07 & 11.38 & 9.20 & 41.87 & 2.76 & 0.53 & 13.89 & 0.12 & 0.70 & 0.02 & 0.01 & 0.35 & 7.67 & 0.01 & 0.16 & 0.05 & & & 732 & & \\
\hline & E122 & $\mathrm{T}$ & L'Hospied & 3.80 & 23.18 & 0.22 & 71.23 & 0.15 & 0.04 & 0.76 & 0.04 & 0.24 & 0.01 & 0.00 & 0.07 & 0.12 & 0.01 & 0.01 & 0.02 & & & 48 & & \\
\hline & E114 & $1 / 20$ & \multirow{2}{*}{ Lacroix } & 15.40 & 8.67 & 15.09 & 57.25 & 0.64 & 0.01 & 1.37 & 0.27 & 0.43 & 0.00 & 0.00 & 0.04 & 0.29 & 0.00 & 0.48 & 0.01 & & & 28 & & \\
\hline & E115 & $\mathrm{T}$ & & 18.25 & 7.72 & 14.64 & 56.47 & 0.65 & 0.01 & 0.46 & 0.26 & 0.43 & 0.00 & 0.01 & 0.05 & 0.84 & 0.01 & 0.17 & 0.01 & & & 79 & & \\
\hline Grisaille & G1 & $\mathrm{O}$ & Granell & 0.00 & 19.95 & 0.04 & 50.41 & 0.20 & 0.03 & 0.53 & 0.14 & 0.08 & 0.02 & 6.52 & 21.87 & 0.00 & 0.03 & 0.00 & 0.00 & & & 97 & & \\
\hline Flux & F1 & & Lacroix & 9.15 & 9.15 & 0.12 & 80.10 & 0.07 & 0.03 & 0.90 & 0.04 & 0.16 & 0.00 & 0.00 & 0.11 & 0.00 & 0.00 & 0.03 & 0.07 & & & 2 & & \\
\hline
\end{tabular}


Table 2. Crystalline compounds determined in the powder and in the enamels. The X-ray Diffraction JCPDS-PDF numbers used for the identification of the compounds are given in square brackets.

\begin{tabular}{|c|c|c|c|c|c|}
\hline Color & Sample & Opacity & Manufacturer & Powder & Enamel \\
\hline \multirow[t]{2}{*}{ Purple } & E14 & $\mathrm{T}$ & \multirow[t]{2}{*}{ Lacroix } & n.d. & $\begin{array}{c}\mathrm{Ag}-\mathrm{Au}-[\mathrm{FM}-3 \mathrm{M}, \mathrm{a}=4.08 \AA] \\
\text { cassiterite }\left(\mathrm{SnO}_{2}\right)-[01-071-0652]\end{array}$ \\
\hline & E107 & $1 / 20$ & & cassiterite $\left(\mathrm{SnO}_{2}\right)-[01-071-0652]$ & cassiterite $\left(\mathrm{SnO}_{2}\right)-[01-071-0652]$ \\
\hline \multirow{3}{*}{ Red } & E23 & $1 / 20$ & \multirow{3}{*}{ Lacroix } & $\begin{array}{c}\mathrm{CdS}-[01-071-1545] \\
\mathrm{Cd}(\mathrm{S}, \mathrm{Se})-[\mathrm{P} 63 \mathrm{mc} \text { with } \mathrm{a}=4.19 \AA \mathrm{c}=6.82 \AA] \\
\mathrm{CdSe}-[01-088-2346], \text { cassiterite }\left(\mathrm{SnO}_{2}\right)-[01-071-0652]\end{array}$ & $\begin{array}{c}\text { CdS- }[01-071-1545] \\
\mathrm{Cd}(\mathrm{S}, \mathrm{Se})-[\mathrm{P} 63 \mathrm{mc} \text { with } \mathrm{a}=4.19 \AA \mathrm{c}=6.82 \AA] \\
\mathrm{CdSe}-[01-088-2346], \text { cassiterite }\left(\mathrm{SnO}_{2}\right)-[01-071-0652]\end{array}$ \\
\hline & $\mathrm{E} 25$ & $\mathrm{~T}$ & & $\begin{array}{c}\text { phoenicochroite }\left(\mathrm{PbO} \cdot \mathrm{Pb}\left(\mathrm{CrO}_{4}\right)\right)-[01-076-0861] \\
\text { cassiterite }\left(\mathrm{SnO}_{2}\right)-[01-071-0652], \mathrm{SiO}_{2}-[01-085-0335] \\
\mathrm{Na}_{2} \mathrm{~B}_{4} \mathrm{O}_{7} \cdot \mathrm{H}_{2} \mathrm{O}^{*}-[01-086-2215], \mathrm{Pb}\left(\mathrm{BO}_{2}\right)_{2} \cdot \mathrm{H}_{2} \mathrm{O}^{*}-[00-007-0011]\end{array}$ & $\begin{array}{l}\text { phoneicochroite }\left(\mathrm{PbO} \cdot \mathrm{Pb}\left(\mathrm{CrO}_{4}\right)\right)-[01-076-0861] \\
\text { cassiterite }\left(\mathrm{SnO}_{2}\right)-[01-071-0652]\end{array}$ \\
\hline & E124 & $\mathrm{T}$ & & n.d. & n.d. \\
\hline \multirow{4}{*}{ Yellow } & E3 & $\mathrm{T}$ & \multirow{4}{*}{ Lacroix } & $\mathrm{Pb}_{3}\left(\mathrm{CO}_{3}\right)^{*}-[01-070-2052]$ & n.d. \\
\hline & E4 & $\mathrm{T}$ & & $\begin{array}{c}\text { phoenicochroite }\left(\mathrm{PbO} \cdot \mathrm{Pb}\left(\mathrm{CrO}_{4}\right)\right)-[01-076-0861] \\
\mathrm{SiO}_{2}-[01-085-0335]\end{array}$ & n.d. \\
\hline & E106 & $1 / 20$ & & $\mathrm{SiO}_{2}-[01-085-0335], \mathrm{Pb}_{2}(\mathrm{Sn}, \mathrm{Sb})_{2} \mathrm{O}_{7}-[01-073-1737]$ & $\mathrm{SiO}_{2}-[01-085-0335], \mathrm{Pb}_{2}(\mathrm{Sn}, \mathrm{Sb})_{2} \mathrm{O}_{7}-[01-073-1737]$ \\
\hline & E119 & $\mathrm{T}$ & & $\begin{array}{l}\text { crocoite } \mathrm{PbCrO}_{4}-[00-008-0209] \\
\text { cassiterite }\left(\mathrm{SnO}_{2}\right)-[01-071-0652]\end{array}$ & n.d. \\
\hline \multirow{3}{*}{ Green } & E34 & $1 / 20$ & \multirow{3}{*}{ Lacroix } & $\begin{array}{c}\mathrm{Co}(\mathrm{Al}, \mathrm{Cr})_{2} \mathrm{O}_{4}-[01-078-0711], \mathrm{Pb}_{2}(\mathrm{Sn}, \mathrm{Sb})_{2} \mathrm{O}_{7}-[01-073-1737] \\
\text { cerussite }\left(\mathrm{PbCO}_{3}\right)^{*}-[01-070-2052]\end{array}$ & $\begin{array}{c}\mathrm{Co}(\mathrm{Al}, \mathrm{Cr})_{2} \mathrm{O}_{4}-[[\mathrm{Fd}-3 \mathrm{~m}, \mathrm{a}=8.333 \AA] \\
\mathrm{Pb}_{2}(\mathrm{Sn}, \mathrm{Sb})_{2} \mathrm{O}_{7}-[01-073-1737]\end{array}$ \\
\hline & E89 & $\mathrm{T}$ & & n.d. & n.d. \\
\hline & E121 & $\mathrm{T}$ & & $\begin{array}{c}\text { phoenicochroite }\left(\mathrm{PbO} \cdot \mathrm{Pb}\left(\mathrm{CrO}_{4}\right)\right)-[01-076-0861] \\
\mathrm{SiO}_{2}-[01-085-0335]\end{array}$ & n.d. \\
\hline \multirow{4}{*}{ Blue } & E33 & $\mathrm{T}$ & Wengers & $\mathrm{CoAl}_{2} \mathrm{O}_{4}-[01-082-2242]$, cerussite $\left(\mathrm{PbCO}_{3}\right)^{*}-[01-070-2052]$ & $\mathrm{CoAl}_{2} \mathrm{O}_{4}-[01-082-2242]$ \\
\hline & E122 & $\mathrm{T}$ & Hospied & $\mathrm{CoAl}_{2} \mathrm{O}_{4}-[01-082-2242]$, cerussite $\left(\mathrm{PbCO}_{3}\right)^{*}-[01-070-2052]$ & n.d. \\
\hline & E114 & $1 / 20$ & \multirow{2}{*}{ Lacroix } & cassiterite $\left(\mathrm{SnO}_{2}\right)-[01-071-0652]$ & cassiterite $\left(\mathrm{SnO}_{2}\right)-[01-071-0652], \mathrm{CoAl}_{2} \mathrm{O}_{4}-[01-082-2242]$ \\
\hline & E115 & $\mathrm{T}$ & & cassiterite $\left(\mathrm{SnO}_{2}\right)-[01-071-0652]$ & cassiterite $\left(\mathrm{SnO}_{2}\right)-[01-071-0652]$ \\
\hline Grisaille & G1 & 0 & Granell & $\begin{array}{l}\text { hematite }\left(\mathrm{Fe}_{2} \mathrm{O}_{3}\right)-[01-072-0469] \\
\text { pyrolusite }\left(\mathrm{MnO}_{2}\right)-[01-072-1984]\end{array}$ & $\begin{array}{c}\text { hematite }\left(\mathrm{Fe}_{2} \mathrm{O}_{3}\right)-[01-072-0469] \\
\text { melanotekite }\left(\mathrm{Pb}_{2}\left(\mathrm{Fe}, \mathrm{Mn}_{2} \mathrm{Si}_{2} \mathrm{O}_{9}\right)-[01-088-1889]\right. \\
\left.\text { bixbyite }(\mathrm{Fe}, \mathrm{Mn})_{2} \mathrm{O}_{3}\right)-[01-071-0636] \\
\text { jacobsite }\left(\mathrm{FeMn} \mathrm{O}_{4}\right)-[01-075-0035]\end{array}$ \\
\hline
\end{tabular}


Table 3. Lab* colour coordinates calculated from the Diffuse Reflectance spectra obtained of the enamels from the Rigalt i Granell workshop.

\begin{tabular}{|c|c|c|c|c|c|c|c|c|c|}
\hline & & & $\lambda_{d}$ & $L^{*}$ & $a^{*}$ & $b^{*}$ & $c^{*}$ & $h^{*}$ & $s^{*}$ \\
\hline \multirow{2}{*}{ Purple } & E14 & \multirow{2}{*}{ Lacroix } & 586 & 18.8 & 3.4 & 5.2 & 6.2 & 56.5 & 31.4 \\
\hline & E107 & & & 31.9 & 2.5 & -3.0 & 4.0 & 309.6 & 12.3 \\
\hline \multirow{3}{*}{ Red } & E23 & \multirow{3}{*}{ Lacroix } & 600 & 36.4 & 19.3 & 12.4 & 22.9 & 32.8 & 53.3 \\
\hline & E25 & & 601 & 40.1 & 31.7 & 23.3 & 39.4 & 36.3 & 70.1 \\
\hline & E124 & & & 18.6 & 1.7 & -0.8 & 1.9 & 334.6 & 10.3 \\
\hline \multirow{4}{*}{ Yellow } & E3 & \multirow{4}{*}{ Lacroix } & 568 & 21.5 & -7.8 & 21.1 & 22.5 & 110.3 & 72.3 \\
\hline & $\mathrm{E} 4$ & & 574 & 21.1 & -0.8 & 8.3 & 8.4 & 95.6 & 36.8 \\
\hline & E106 & & 572 & 19.1 & -2.1 & 8.2 & 8.4 & 104.6 & 40.5 \\
\hline & E119 & & 566 & 26.2 & -7.5 & 14.8 & 16.6 & 116.9 & 53.4 \\
\hline \multirow{3}{*}{ Green } & E34 & \multirow{3}{*}{ Lacroix } & 489 & 31.0 & -13.2 & -7.0 & 15.0 & 208.0 & 43.5 \\
\hline & E89 & & 502 & 24.1 & -10.3 & 1.4 & 10.4 & 172.3 & 39.5 \\
\hline & E121 & & 497 & 7.1 & -1.6 & -0.1 & 1.6 & 181.9 & 22.2 \\
\hline \multirow{4}{*}{ Blue } & E33 & Wengers & 469 & 11.9 & 6.7 & -17.8 & 19.1 & 290.7 & 84.8 \\
\hline & E122 & Hospied & 482 & 31.3 & -1.6 & -5.1 & 5.4 & 252.6 & 16.9 \\
\hline & E114 & \multirow{2}{*}{ Lacroix } & 478 & 24.1 & -0.3 & -19.0 & 19.0 & 269.0 & 61.9 \\
\hline & E115 & & 469 & 22.5 & 5.4 & -15.6 & 16.5 & 289.2 & 59.1 \\
\hline Grisaille & G1 & Granell & 601 & 40.4 & 47.8 & 48.3 & 67.9 & 45.3 & 85.9 \\
\hline
\end{tabular}


Table 4. Chemical analysis performed by LA-ICP-MS from the base glasses and from the purple and blue enamels from Palau de Justicia and from the Seu del Districte de Sants-Montjuic respectively (Rigalt i Granell) and of the base and red glasses and yellow and green enamels from Estació del Nord (Maumejan)

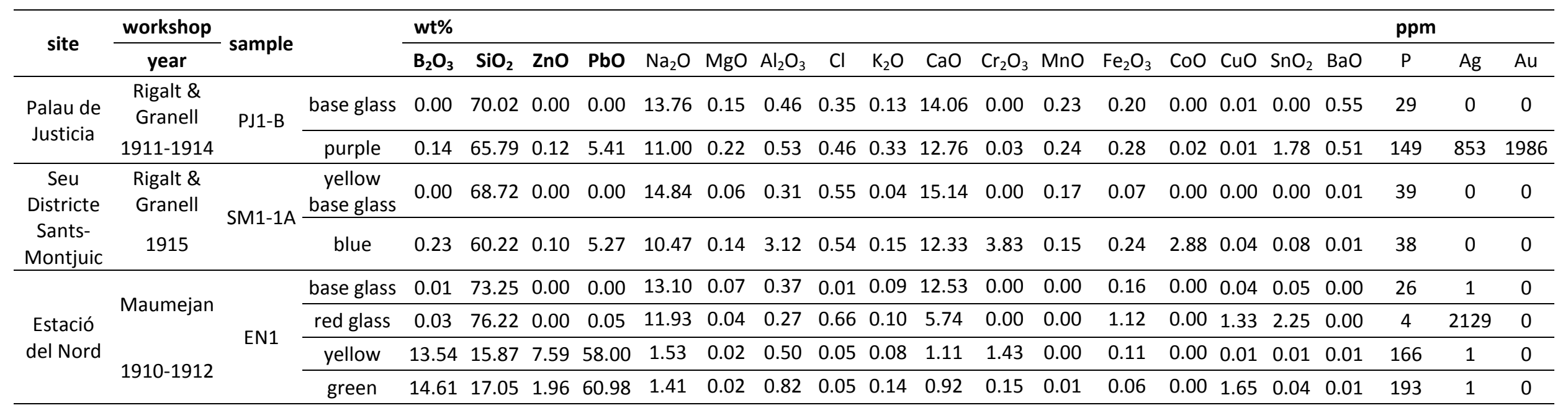


Table 5. Lab* colour coordinates calculated from the Diffuse Reflectance spectra obtained of the historical enamels.

\begin{tabular}{cccccccccc}
\hline & & $\lambda_{d}$ & $L^{*}$ & $a^{*}$ & $b^{*}$ & $c^{*}$ & $h^{*}$ & $s^{*}$ \\
\hline \multirow{3}{*}{ Rigalt \& Granell } & \multirow{2}{*}{ PJ1 } & Purple & 611 & 27.7 & 4.3 & 1.6 & 4.6 & 20.3 & 16.3 \\
\cline { 2 - 10 } & & Grissaille & 586 & 24.0 & 1.4 & 2.0 & 2.5 & 55.8 & 10.2 \\
\cline { 2 - 10 } Maumejan & Blue & 483 & 25.9 & -1.4 & -3.5 & 3.8 & 248.1 & 14.4 \\
\hline \multirow{3}{*}{ EN1 } & Yellow & 576 & 29.6 & -0.2 & 5.7 & 5.7 & 91.9 & 19.0 \\
\cline { 2 - 9 } & & Green & 570 & 31.8 & -2.1 & 5.9 & 6.3 & 109.5 & 19.4 \\
\cline { 2 - 9 } & & Grissaille & 592 & 29.9 & 3.1 & 2.7 & 4.1 & 40.6 & 13.7
\end{tabular}


Figure 1

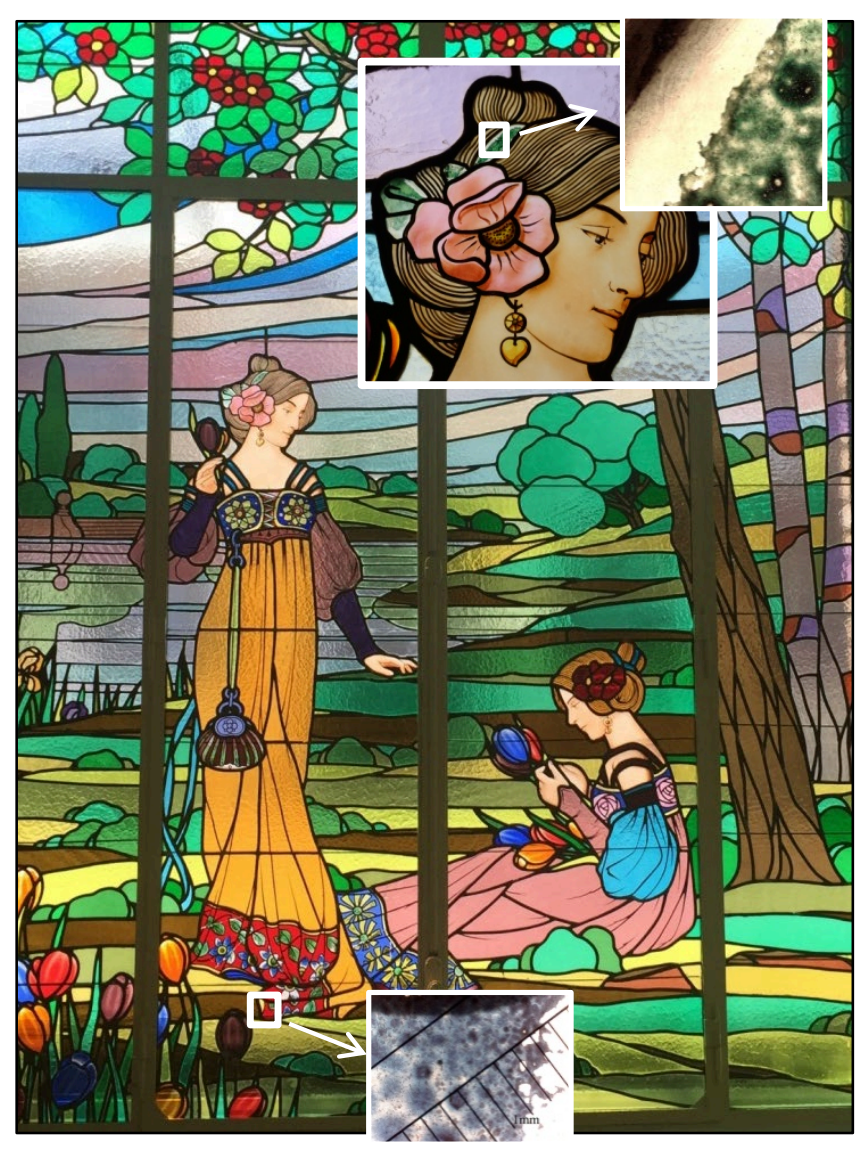




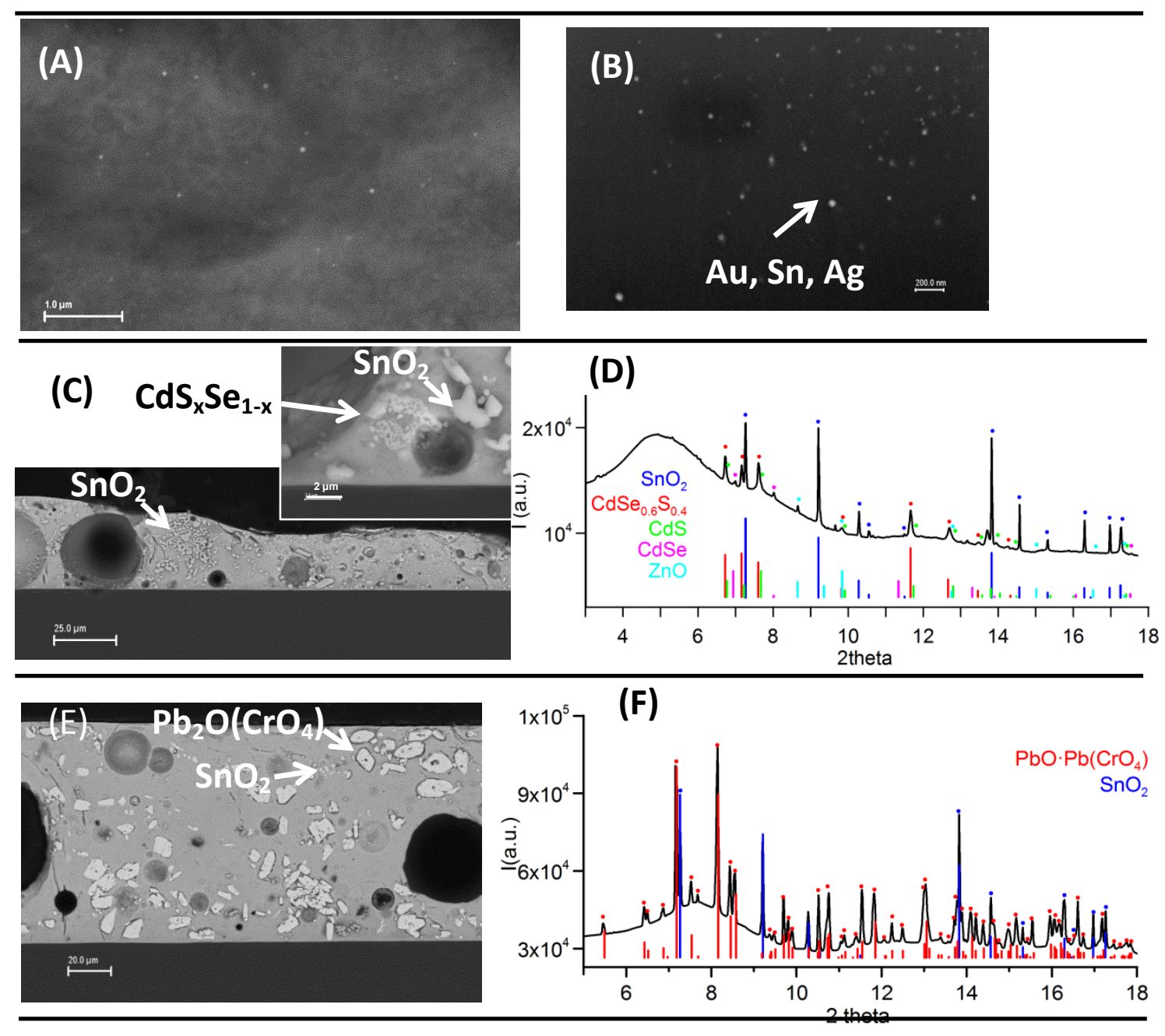


Figure 3

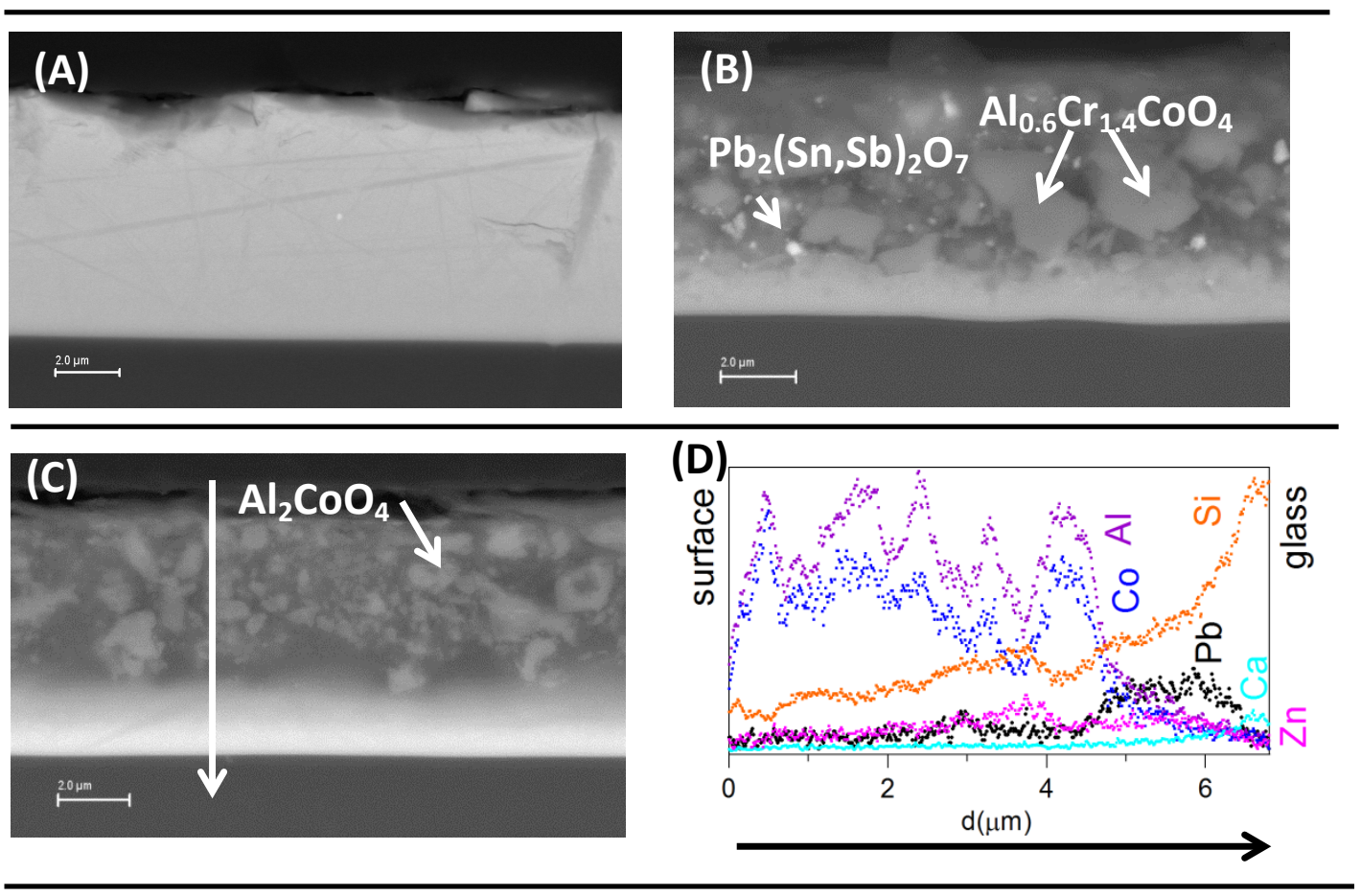


Figure 4

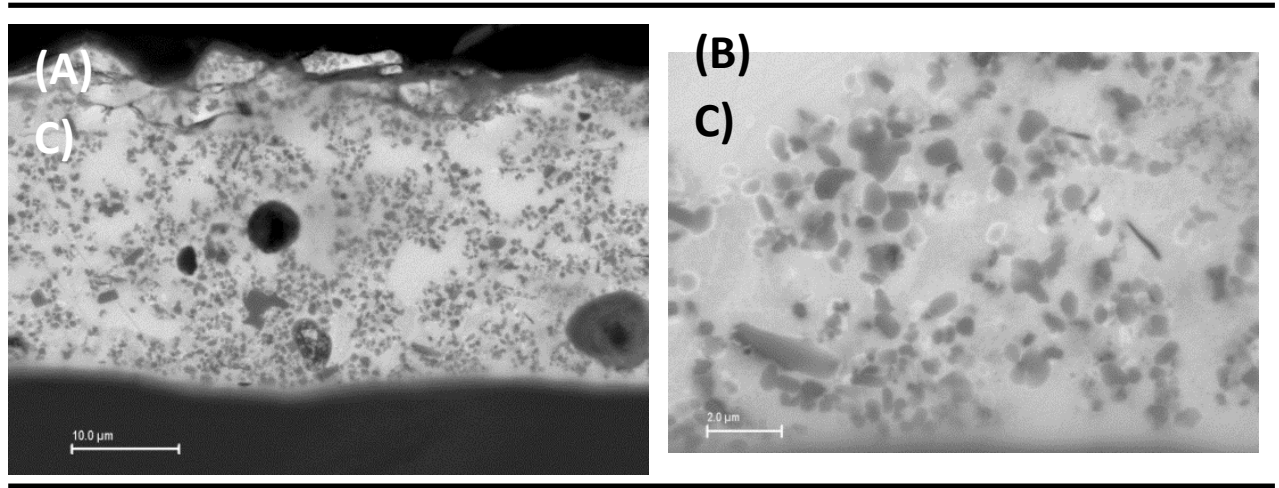

(C)

Haematite - $\mathrm{Fe}_{2} \mathrm{O}_{3}$

C) Jacobsite - $\mathrm{FeMn}_{2} \mathrm{O}_{4}$ Bixbyite - $(\mathrm{Fe}, \mathrm{Mn})_{2} \mathrm{O}_{3}$

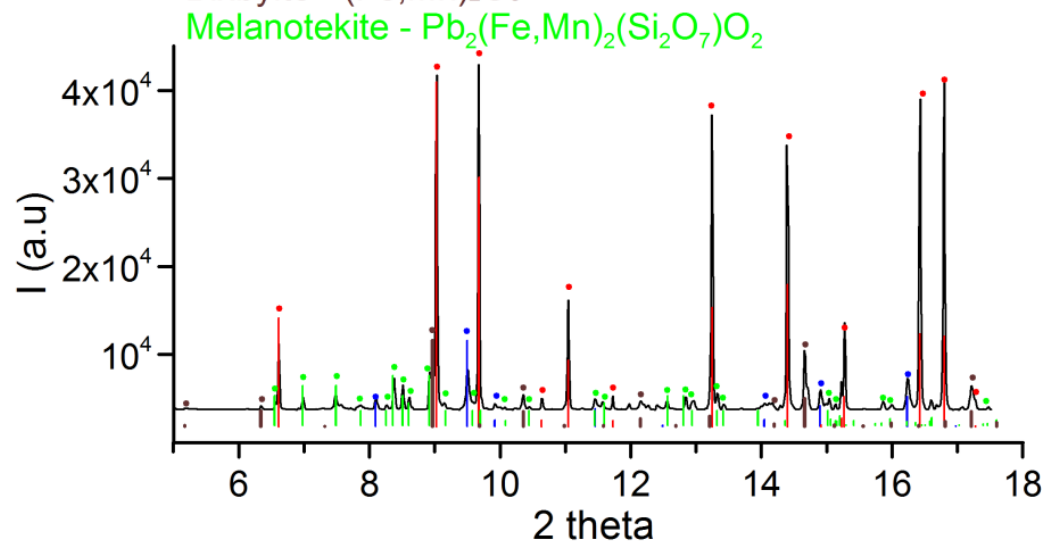


Figure 5

(A)

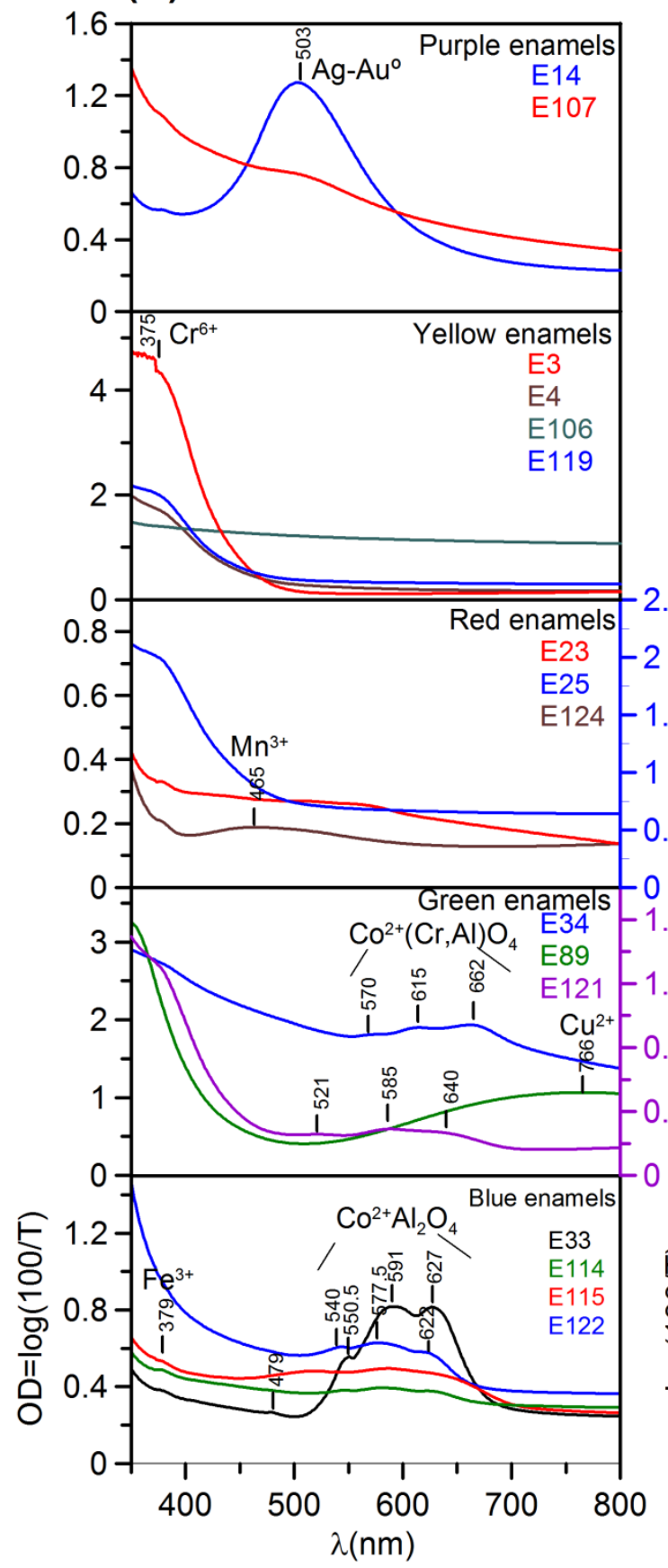

(B)

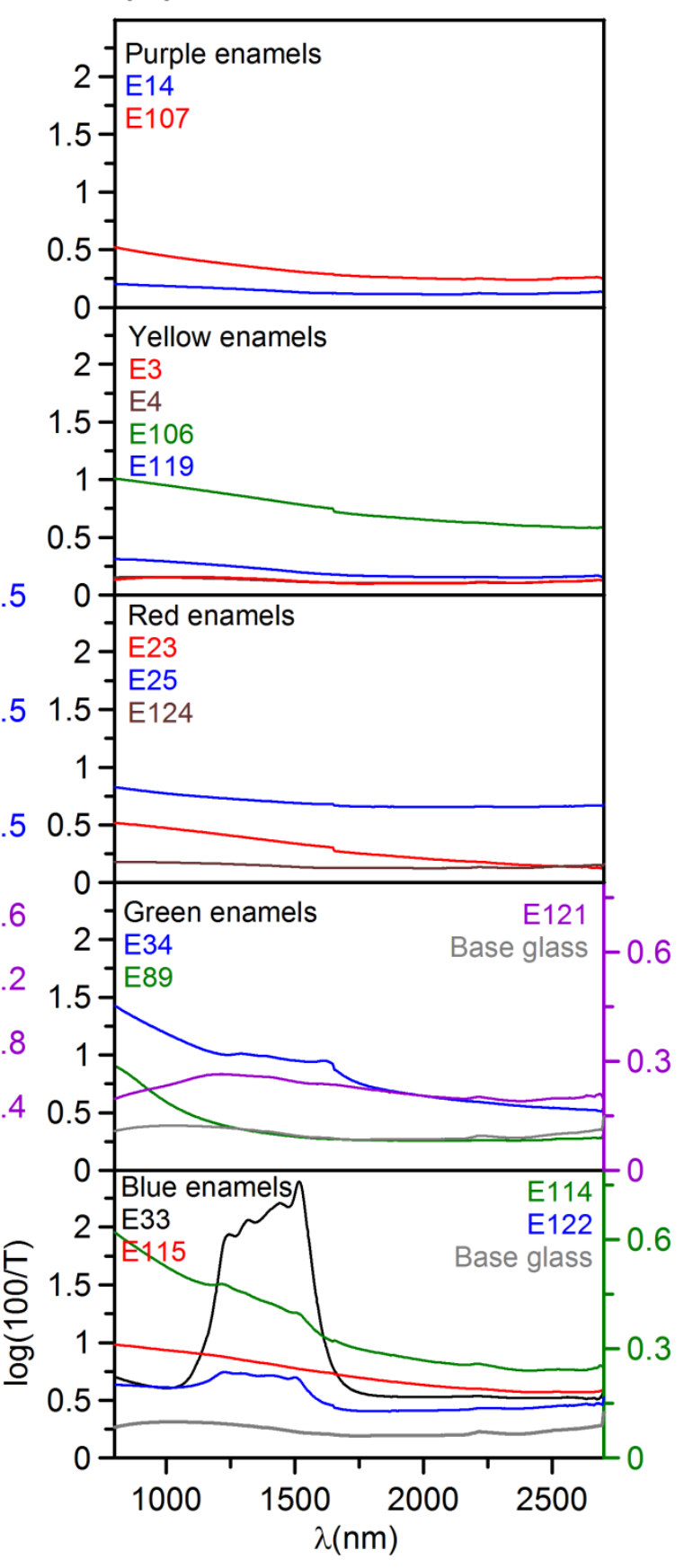


Figure 6

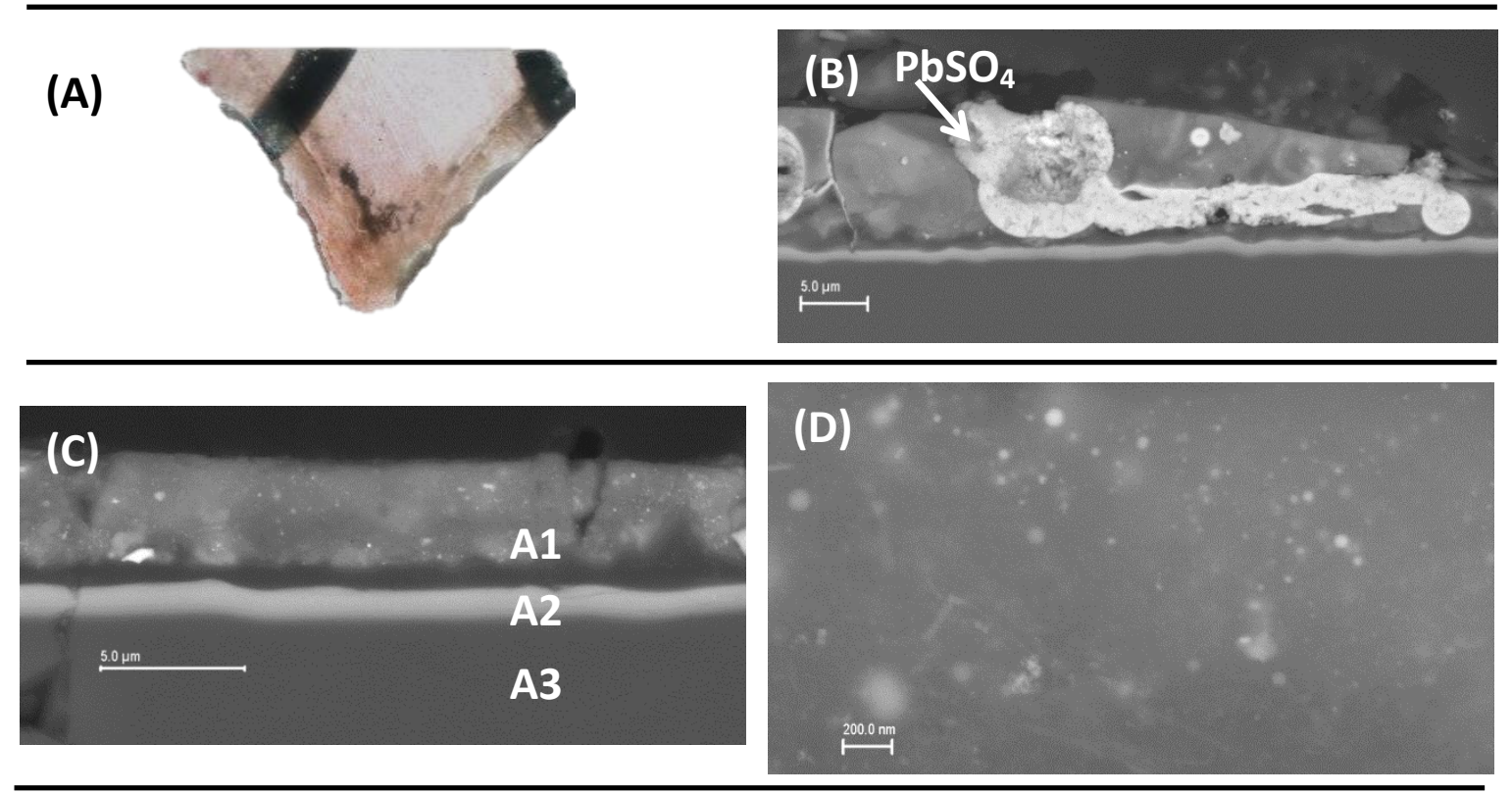

(E)

\begin{tabular}{|c|c|c|c|c|c|c|c|c|c|c|c|c|c|c|c|c|c|}
\hline wt\% & $\mathrm{Na}_{2} \mathrm{O}$ & $\mathrm{MgO}$ & $\mathrm{Al}_{2} \mathrm{O}_{3}$ & $\mathrm{SiO}_{2}$ & $\mathrm{SO}_{3}$ & $\mathrm{Cl}$ & $\mathrm{K}_{2} \mathrm{O}$ & $\mathrm{CaO}$ & $\mathrm{MnO}$ & $\mathrm{FeO}$ & $\mathrm{ZnO}$ & $\mathrm{SnO}_{2}$ & $\mathrm{Ag}$ & $\mathrm{Au}$ & $\mathrm{PbO}$ & $\mathrm{BaO}$ & Total \\
\hline A1 & 1.2 & 0.3 & 1.5 & 44.6 & 1.7 & 0.2 & 1.3 & 1.4 & & 1.0 & 0.6 & 14.9 & 0.5 & 2.6 & 7.2 & & 77.7 \\
\hline A2 & 7.5 & 0.3 & 0.5 & 55.2 & & 0.4 & 0.5 & 6.0 & & & & 1.7 & & & 28.0 & & 99.4 \\
\hline A3 & 13.6 & 0.19 & 0.3 & 68.5 & 1.0 & 0.4 & 0.2 & 14.2 & 0.3 & & & & & & & 0.5 & 99.1 \\
\hline
\end{tabular}
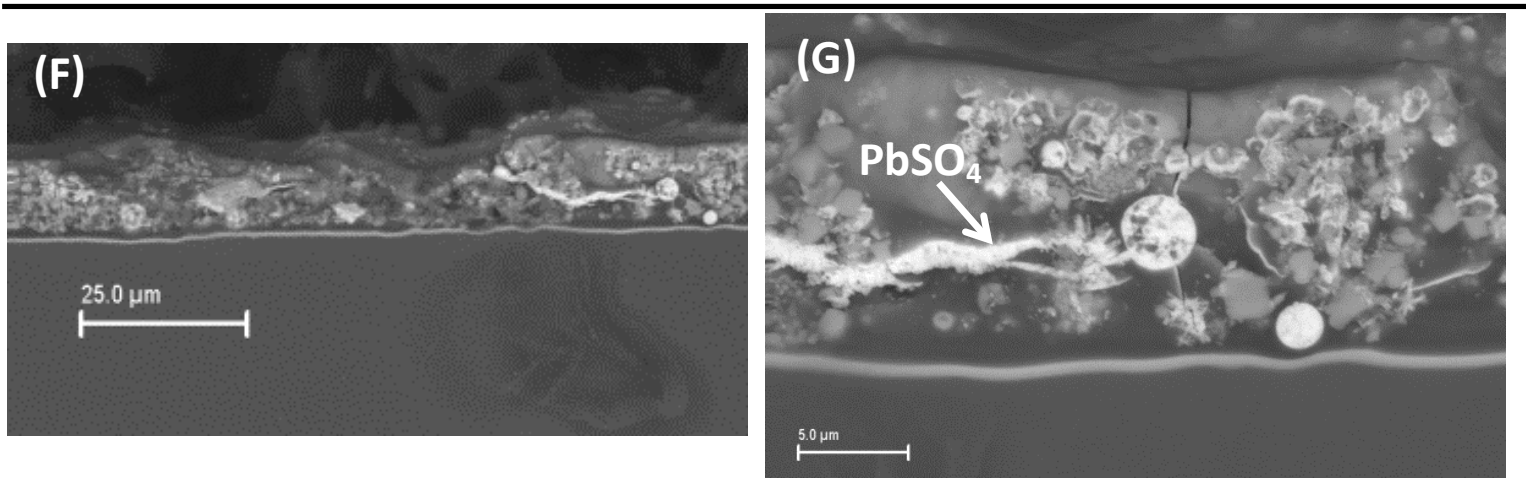

(H)

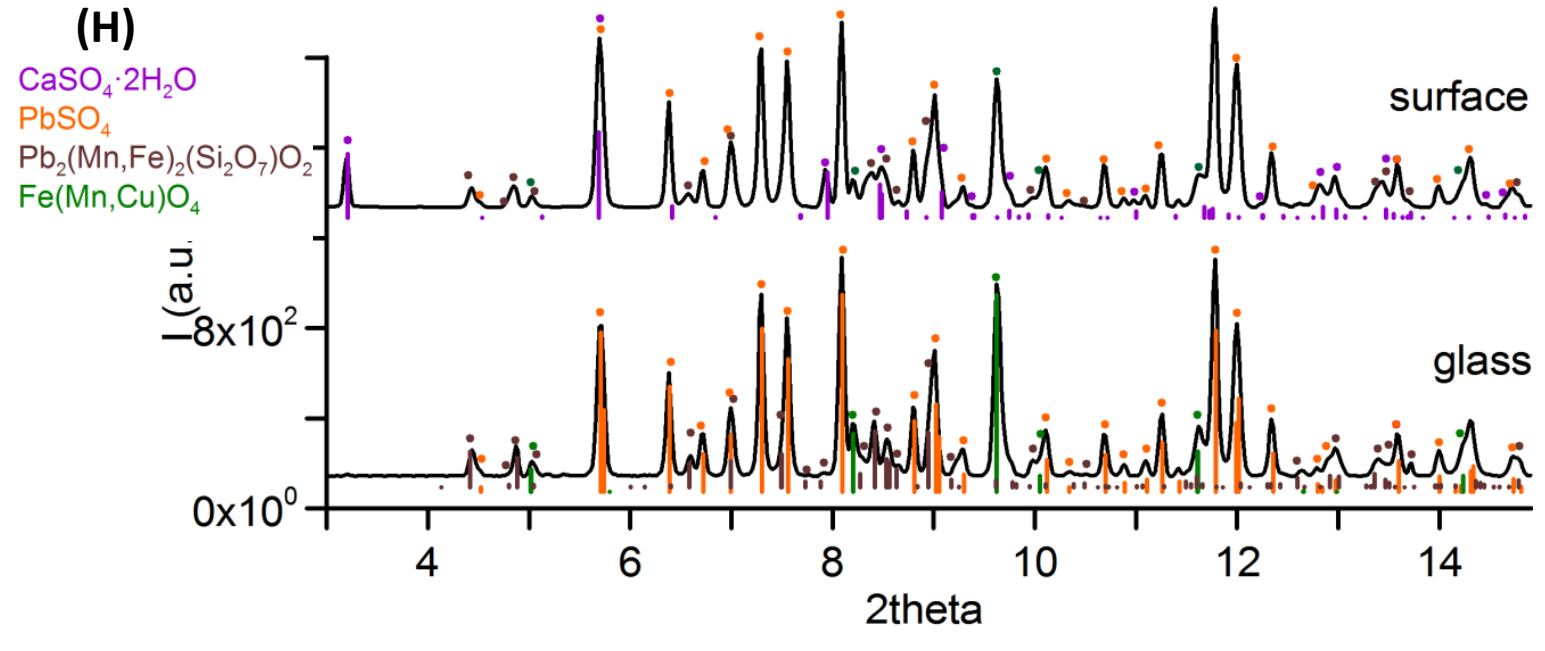


Figure 7

(A)

(B) $(\mathrm{Al}, \mathrm{Cr})_{2} \mathrm{CoO}_{4} \mathrm{~Pb}_{2}(\mathrm{Mn}, \mathrm{Fe})_{2}\left(\mathrm{Si}_{2} \mathrm{O}_{7}\right) \mathrm{O}_{2}$
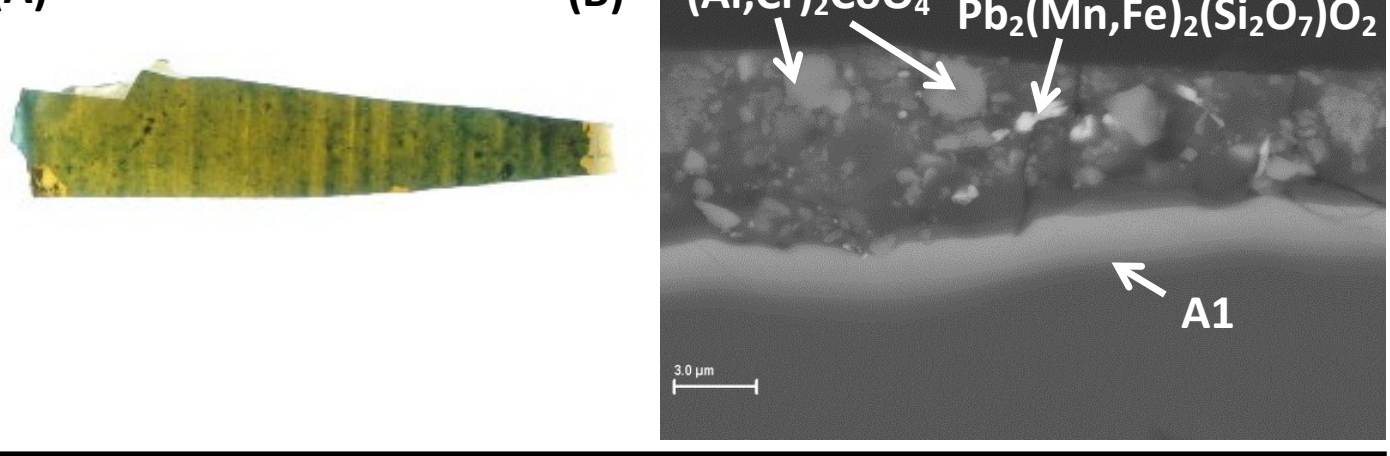

(C) \begin{tabular}{ccccccccccccc} 
wt\% & $\mathrm{Na}_{2} \mathrm{O}$ & $\mathrm{MgO}$ & $\mathrm{Al}_{2} \mathrm{O}_{3}$ & $\mathrm{SiO}_{2}$ & $\mathrm{Cl}$ & $\mathrm{K}_{2} \mathrm{O}$ & $\mathrm{CaO}$ & $\mathrm{FeO}$ & $\mathrm{Cr}_{2} \mathrm{O}_{3}$ & $\mathrm{CoO}$ & $\mathrm{PbO}$ & Total \\
\hline $\mathbf{A 1}$ & 6.4 & 0.5 & 0.2 & 47.8 & 0.5 & 0.2 & 6.9 & 0.3 & 0.1 & 0.4 & 36.5 & 99.1
\end{tabular}

(D)
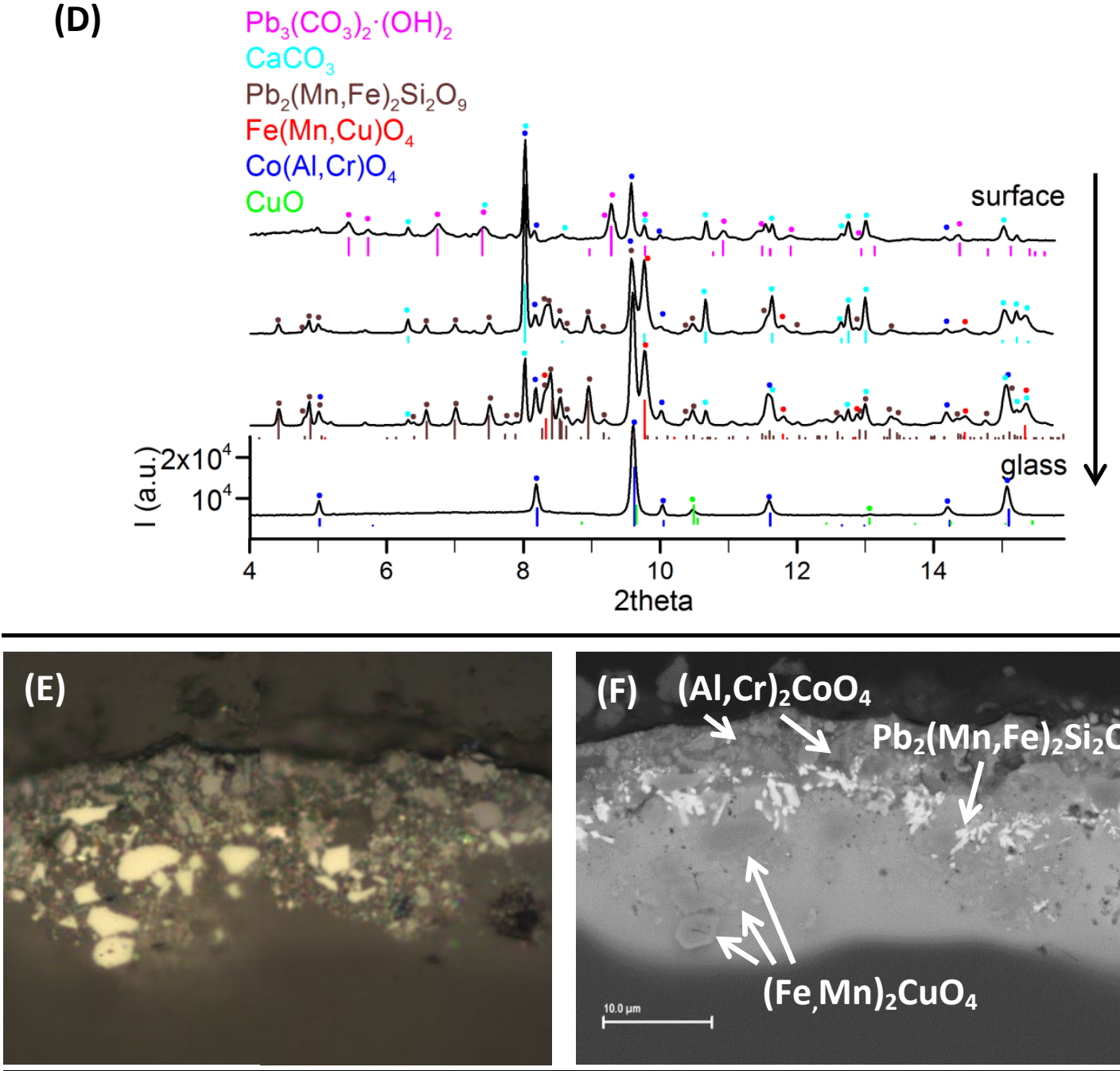

(F) $(\mathrm{Al}, \mathrm{Cr})_{2} \mathrm{CoO}_{4}$

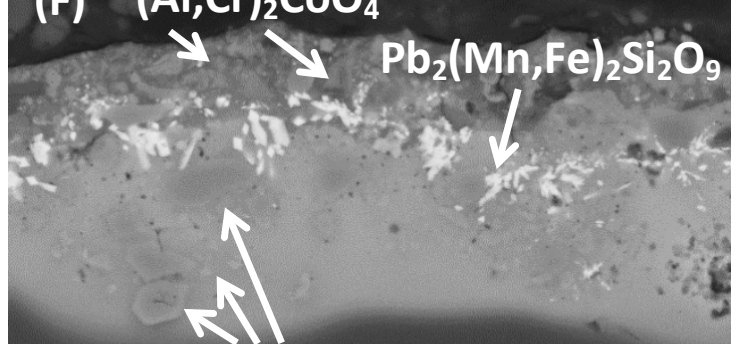

$(\mathrm{Fe}, \mathrm{Mn})_{2} \mathrm{CuO}_{4}$ 
Figure 8

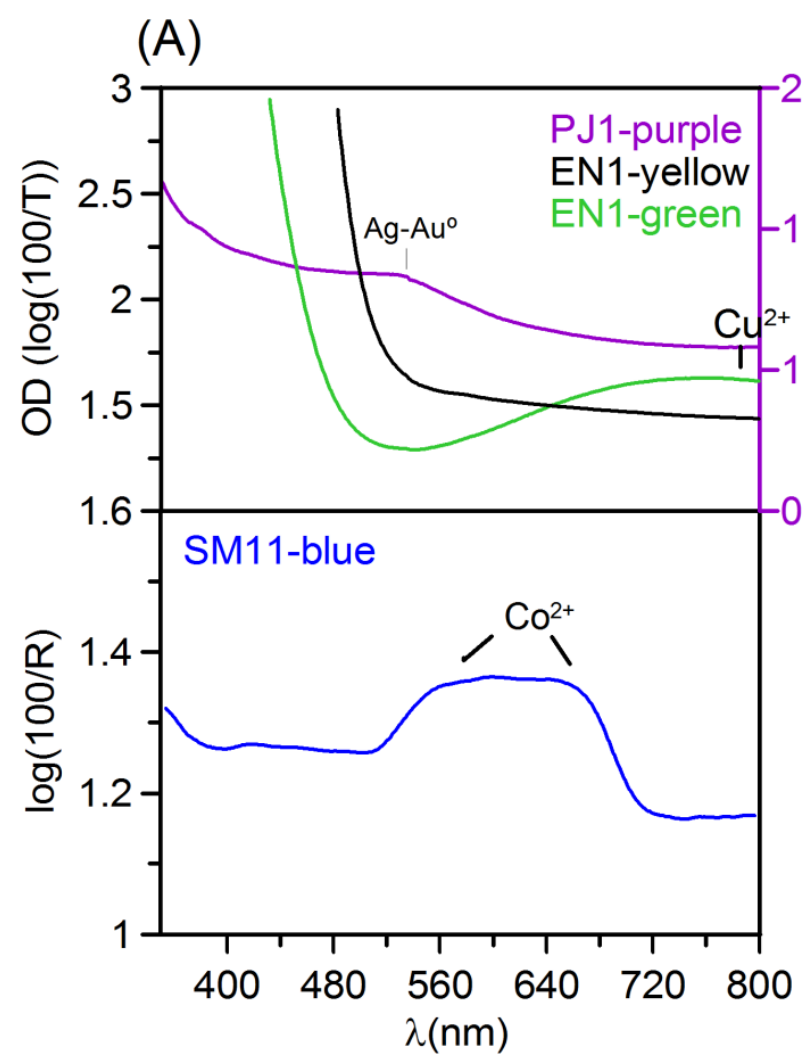

(B)

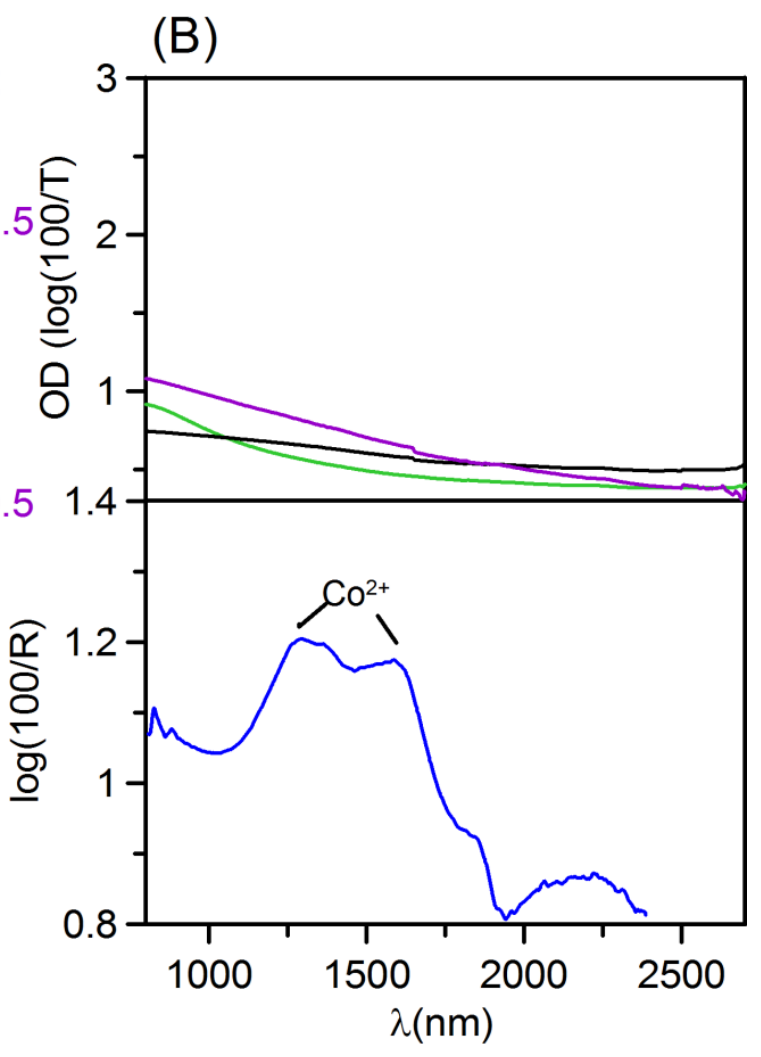

